NBER WORKING PAPER SERIES

THE SLOWDOWN IN THE ECONOMIC ASSIMILATION OF IMMIGRANTS:

AGING AND COHORT EFFECTS REVISITED AGAIN

\author{
George J. Borjas \\ Working Paper 19116 \\ http://www.nber.org/papers/w19116 \\ NATIONAL BUREAU OF ECONOMIC RESEARCH \\ 1050 Massachusetts Avenue \\ Cambridge, MA 02138 \\ June 2013
}

I am grateful to Daniel Hamermesh, Lawrence Kahn, James Smith and Stephen Trejo for valuable comments on an earlier draft of this paper, and to the MacArthur Foundation for financial support. The views expressed herein are those of the author and do not necessarily reflect the views of the National Bureau of Economic Research. The views expressed herein are those of the author and do not necessarily reflect the views of the National Bureau of Economic Research.

NBER working papers are circulated for discussion and comment purposes. They have not been peerreviewed or been subject to the review by the NBER Board of Directors that accompanies official NBER publications.

(C) 2013 by George J. Borjas. All rights reserved. Short sections of text, not to exceed two paragraphs, may be quoted without explicit permission provided that full credit, including $(\mathbb{C}$ notice, is given to the source. 
The Slowdown in the Economic Assimilation of Immigrants: Aging and Cohort Effects Revisited Again

George J. Borjas

NBER Working Paper No. 19116

June 2013, Revised May 2014

JEL No. J24,J60,J61

\begin{abstract}
This paper examines the evolution of immigrant earnings in the United States between 1970 and 2010. There are cohort effects not only in wage levels, with more recent cohorts having lower entry wages through 1990, but also in the rate of wage growth, with more recent cohorts experiencing less economic assimilation. The slowdown in assimilation is partly related to a concurrent decline in the rate at which the new immigrants add to their human capital stock, as measured by English language proficiency. The data also suggest that the rate of economic assimilation is significantly lower for larger national origin groups.
\end{abstract}

George J. Borjas

Harvard Kennedy School

79 JFK Street

Cambridge, MA 02138

and NBER

gborjas@harvard.edu 


\title{
The Slowdown in the Economic Assimilation of Immigrants: Aging and Cohort Effects Revisited Again
}

\author{
George J. Borjas ${ }^{*}$
}

\section{Introduction}

The economic impact of immigration ultimately depends on the skill composition of the immigrant population. Not surprisingly, much of the research in the economics of immigration focuses on examining the evolution of skills in the foreign-born workforce, both in terms of their pre-existing human capital (which depends on the decision rule that selects the immigrants from the population of the source countries) and in terms of the rate at which immigrants acquire additional skills in the post-migration period.

Beginning with Chiswick (1978), there has been a great deal of empirical research that attempts to measure the extent of economic assimilation, defined as the rate of wage convergence between immigrants and natives. The initial studies in this literature used crosssection data sets to compare the age-earnings profiles of immigrants and natives, and typically found a very rapid rate of wage convergence. Borjas $(1985,1995)$ emphasized that the crosssection comparison may not properly measure the true rate of assimilation because there may be substantial differences in earnings potential across immigrant cohorts. In fact, the Borjas studies documented the presence of sizable "cohort effects": newly arrived immigrant cohorts in the United States (at least through 1990) had relatively lower entry earnings than earlier cohorts. Not surprisingly, accounting for these cohort effects in wage levels substantially reduces the rate of economic assimilation implied by the cross-section comparison.

This paper uses data from the 1970-2010 decennial censuses to examine the evolution of immigrant earnings in the United States. The long-term trends in the data clearly reveal a potentially important new finding. There are cohort effects not only in the level of earnings, with more recent cohorts having relatively lower entry wages (through 1990), but there also exist cohort effects in the rate of growth of earnings, with more recent cohorts having a smaller rate of economic assimilation than earlier cohorts. Immigrants who entered the country before the 1980s typically found that their initial wage disadvantage (relative to natives) narrowed by 15 percentage points during their first two decades in the United States. In contrast, the immigrants who entered the country after the 1980s have a much lower rate of wage convergence. In fact, the evidence suggests that there has not been any economic assimilation for the cohorts that entered the country in the 1990s.

The paper evaluates a number of alternative hypotheses that may explain the onset of these cohort effects in the rate of wage convergence. These hypotheses include the possibility that changes in macroeconomic conditions affect the immigrant and native wage structures differently, precluding the possibility of much earnings growth for immigrant workers; the hypothesis that the changing national origin composition of the immigrant population may lead, on average, to lower assimilation rates; the premise that the geographic settlement of newer immigrant waves in different regions of the United States may have affected assimilation trends;

\footnotetext{
* Robert W. Scrivner Professor of Economics and Social Policy, Harvard Kennedy School; Research Associate, National Bureau of Economic Research; and Research Fellow, IZA. I am grateful to Edward Glaeser, Daniel Hamermesh, Lawrence Kahn, Lawrence Katz, James Smith, and Stephen Trejo for valuable comments on an earlier draft of this paper, and to the MacArthur Foundation for financial support.
} 
and the possibility that the labor supply effects of the Great Recession generate selection biases that differentially affect the rates of wage growth for immigrants and natives. The data convincingly show that none of these factors can account for the severe decline in the rate of assimilation.

Instead, the analysis suggests that at least part of the decline in assimilation reflects a detectable reduction in the actual rate of human capital accumulation. Although the available data provides only limited information on the acquisition of human capital in the post-migration period, the data reveal a concurrent decline in the rate at which the newer immigrant cohorts are "picking up" English language skills. The cohorts that entered the country prior to the 1980s typically experienced a 12-percentage point increase in their fluency rate during their first decade, while the cohorts that entered the country after the 1980s show only a 4-percentage point increase.

Finally, the study identifies one factor that seems to explain part of the decline in the rate of economic assimilation: the rapid growth in the size of specific national origin groups in the United States. The rate of increase in English language proficiency is significantly slower for larger national origin groups. As a result, the growth in the size of the groups accounts for about a quarter of the concurrent declines in the rate of economic assimilation and the rate of human capital acquisition.

Given the potential significance of these findings, it is wise to interpret the results cautiously. Although the evidence from the decennial census data is unambiguous, much further analysis is required before we can assert conclusively that the economic assimilation of immigrants slowed down dramatically in the past few decades. Perhaps most important, it is crucial to replicate the findings in the context of longitudinal samples rather than the repeated cross-sections available in census data. Nevertheless, if the evidence presented in this paper can be confirmed in other data sets, the results suggest a hypothesis that is sure to attract widespread interest: the more recent immigrant cohorts have fewer incentives to invest in U.S.-specific human capital because the growth of the immigrant population makes those investments less profitable than they once were, and those reduced incentives have slowed the rate of economic assimilation.

\section{Empirical Evidence on Aging and Cohort Effects}

It is instructive to begin by documenting the basic patterns revealed by the data over the past few decades. Specifically, I use all available decennial census data between 1970 and 2000, as well as the pooled 2009-2011 American Community Surveys. ${ }^{1}$ For expositional convenience, I will often refer to the pooled ACS surveys as the "2010 census." In each cross-section, the sample consists of men aged 25-64 as of the time of the survey, who have between 1 and 40 years of labor market experience, worked at some point during the survey year, and are not enrolled in school. ${ }^{2}$ In addition, the immigrant sample is restricted to persons who migrated to

1 The 1970 Census cross-section represents a 3 percent random sample of the population obtained by pooling the State, Metropolitan Area, and Neighborhood Form 1 files. The 1980-2000 cross-sections represent a 5 percent random sample, and the pooled 2009-2011 ACS represents a 3 percent random sample. The data were downloaded from the Integrated Public Use Microdata Series (IPUMS) website in March 2013. All calculations reported in this paper use the Census-provided sampling weights.

2 The "survey year" refers to the calendar year prior to the census in the decennial census data, and to the 52-week period prior to the survey in the pooled ACS data. To calculate a worker's years of experience I assume that the age of labor market entry is 17 for high school dropouts, 19 for high school graduates, 21 for workers with 
the United States after age $18 .^{3}$ The dependent variable is the log weekly earnings of the worker, where weekly earnings are defined by the ratio of total earned income to weeks worked.

I estimate the following regression model in each of the census cross-sections:

$$
\log w_{\ell \tau}=\phi_{c \tau}+X_{\ell \tau} \beta_{\tau}+\varepsilon_{\ell \tau}
$$

where $w_{\ell \tau}$ represents the weekly earnings of person $\ell$ in cross-section $\tau ; X$ is a vector of variables giving the worker's age introduced as a third-order polynomial; and $\phi_{c \tau}$ is a vector of fixed effects indicating a specific immigrant cohort in the particular cross-section (with the native fixed effect being excluded from the regression). Note that since the immigrant sample only includes persons who migrated to the United States after they were 18 years old, the tracking of specific cohorts across Censuses is not contaminated by the "late entry" in later censuses of persons who migrated as children.

Table 1 reports the estimated cohort fixed effects. ${ }^{4}$ An examination of these age-adjusted wage gaps reveals two interesting findings. The first, which has received a great deal of attention in the literature, is the existence of numerically sizable cohort effects in wage levels, with the more recent cohorts having relatively lower earnings potential than earlier cohorts (through 1990). Consider, for example, the trend in the wage gap between the most recent cohort of immigrants and natives in each cross-section. In 1970, the most recent immigrant wave earned 23.5 percent less than comparable natives. By 1990, the entry wag disadvantage had grown to 33.1 percent, before contracting to 27.3 percent in $2000 .{ }^{5}$ By 2010 , however, the long-run trend in level cohort effects seems to have returned, and the latest wave of immigrants earned almost 33 percent less than comparable natives. If we assume that changes in aggregate economic conditions do not affect the relative wage of immigrants, the trend in the relative entry wage across cross-sections can then be attributed to shifts in the relative skills of successive immigrant cohorts.

Define the rate of economic assimilation as the rate at which the wage gap between immigrants and natives narrows over time. In addition to the cohort effects in wage levels, the age-adjusted wage gaps reported in Table 1 suggest another interesting (and potentially important) finding, one that has not yet been noted in the literature: there seems to have been a "break" in the late 1980s in the rate of economic assimilation experienced by immigrants. Specifically, the immigrants who arrived on or after 1985 experience far less economic assimilation than earlier arrivals. Put differently, the data suggest the presence of cohort

some college, 23 for college graduates, and 24 for persons with a post-college education. A worker's years of experience is then given by the difference between age at the time of the survey and the age of entry into the labor market.

${ }^{3}$ A person is classified as "immigrant" if he is either a non-citizen or a naturalized citizen. All other persons are classified as "natives."

${ }^{4}$ The entry years of the cohorts defined in Table 1 are the ones that are easiest to identify consistently across cross-sections. Note that the restriction that the sample consists of persons who worked in the survey year implies that the immigrants must have arrived prior to the census year in the decennial census data.

${ }^{5}$ Borjas and Friedberg (2009) analyze the uptick in the relative entry wage of the 1995-1999 cohort and conjecture that it may be partly due to the temporary expansion of the high-tech $\mathrm{H}-1 \mathrm{~B}$ visa program in the late 1990s. 
differences not only in the level of immigrant earnings, but in the rate of growth of immigrant earnings as well. ${ }^{6}$

Suppose again that changes in aggregate economic conditions do not affect the relative wage of immigrants. The cohort effects in the rate of economic assimilation can then be detected by "tracking" a specific cohort across Censuses. Consider, for instance, the cohort that entered the country between 1975 and 1979. The relative wage of this group improved from a disadvantage of 31.4 percent at the time of entry in 1980, to 18.5 percent in 1990, and to 17.6 percent by 2000 - a growth of about 14 percentage points over their first two decades in the United States (with much of it occurring in the first 10 years). In contrast, the cohort that entered the country between 1985 and 1989 earned 33.1 percent less than natives at the time of entry and this wage disadvantage improved by only 4 percent points between 1990 and 2000, and by another percentage point between 2000 and 2010. Finally, consider the cohort that entered the country between 1995 and 1999. Their wage disadvantage stood at about 27 percent both in 2000 and 2010, so that this cohort experienced no relative wage growth whatsoever during their first 10 years in the United States.

Figure 1 illustrates the substantive importance of the cohort effects in wage growth by graphing the (normalized) wage gaps reported in Table 1. As the figure shows, there has been a dramatic flattening in the slope of the (relative) age-earnings profile across subsequent immigrant cohorts.

The raw data, therefore, provide strong evidence of cohort effects in both the level and rate of growth in immigrant earnings. It is well known that the separate identification of aging and cohort effects raises difficult methodological problems in many demographic contexts. Obviously, identification requires the availability of longitudinal data where a particular worker is observed over time, or, equivalently, the availability of a number of randomly drawn crosssections so that the average member of a specific cohort can be "tracked" across survey years. It is easy to construct a regression model that accounts for aging effects and cohort effects in both wage levels and wage growth. To illustrate, suppose two cross-section surveys are available, with cross-section $\tau(\tau=1,2)$ being observed in calendar year $T_{\tau}$. Stack the data for immigrants and natives across the cross-sections and consider the two-equation regression model:

Immigrant earnings function:

Native earnings function:

$$
\begin{aligned}
& \log w_{\ell}=X_{\ell}+y_{\ell}+C_{\ell}+\left(y_{\ell} C_{\ell}\right)+{ }_{i}{ }_{\ell 2}+{ }_{\ell} \\
& \log w_{\ell}=X_{\ell}{ }_{n}+{ }_{n \ell 2}+{ }_{\ell}
\end{aligned}
$$

where $C_{\ell \tau}$ gives the calendar year in which the immigrant arrived in the host country; $y_{\ell \tau}$ gives the number of years that the immigrant has resided in the host country $\left(y_{\ell \tau}=T_{\tau}-C_{\ell}\right)$; and $\pi_{\ell 2}$ is an indicator variable indicating if person $\ell$ was drawn from cross-section 2.

Since the vector $X$ includes the worker's age, the parameter $\alpha$ in the immigrant earnings function measures the "excess" value of acquiring a year of experience in the United States, and represents an aging effect; the coefficient $\beta$ indicates how the earnings of immigrants are changing across cohorts, and measures the cohort effect on the level of earnings potential; the

6 Interestingly, Aydemir and Skuterud's (2005) study of earnings trends in Canada also finds a break in the rate of immigrant assimilation after 1990, but in the opposite direction. The post-1990 immigrants in Canada have much lower entry earnings than earlier waves, but a faster rate of wage convergence. 
coefficient $\theta$ is positive or negative depending on whether more recent cohorts have a larger or smaller rate of wage growth, capturing cohort effects in the rate of economic assimilation; and the coefficients $\gamma_{i}$ and $\gamma_{n}$ give the impact of changes in aggregate economic conditions on immigrant and native wages, respectively, and measure period effects. Although equations $(2 a)$ and $(2 b)$ build in a simple parameterization of the aging and cohort effects, it is trivial to incorporate a more general specification of these effects in empirical work.

It is well known that the parameters measuring the aging, cohort, and period effects in (2a) are not separately identified. The identification problem arises from the identity:

$$
y_{\ell} \quad T_{1}+{ }_{\ell 2}\left(T_{2} \quad T_{1}\right) \quad C_{\ell} .
$$

Equation (3) introduces perfect collinearity among the variables $y_{\ell \tau}, C_{\ell}$, and $\pi_{\ell 2}$ in the immigrant earnings function. To identify the parameters of interest, therefore, not only is it necessary to have a panel of data where immigrant cohorts or specific workers can be tracked over time, but also impose some additional restriction that breaks the perfect collinearity in equation (3). Borjas (1985) proposed the restriction that the period effects were the same for immigrants and natives:

$$
\gamma_{i}=\gamma_{n}
$$

Put differently, trends in aggregate economic conditions change immigrant and native wages by the same percentage amount. A useful way of thinking about this restriction is that the period effect for immigrants, $\gamma_{i}$, is determined outside the immigrant-specific labor market. ${ }^{7}$

The empirical analysis reported below expands the interactive framework suggested by equation $(2 a)$ in several ways. First, the regression pools data from the five cross-sections available between 1970 and 2010, so that the period effects are captured by a vector of fixed effects indicating the cross-section from which a particular observation is drawn. Second, the years-since-migration variable $y$ is introduced as a third-order polynomial. Third, the continuous calendar year of entry variable $C$ is replaced by a vector of fixed effects indicating a "period" of entry (i.e., the various entry cohorts defined in Table 1). Finally, the cohort effects in wage growth are captured by interacting the linear term of the years-since-migration variable with each of the period-of-entry fixed effects. ${ }^{8}$ Put differently, each entry cohort is allowed to have its own growth path.

The first column of Table 2 presents selected coefficients from the regression model, Although the regression model contains the full set of cohort fixed effects listed in Table 1 (and the interactions of these cohort fixed effects with the years-since-migration variable), I only

\footnotetext{
${ }^{7}$ For example, the value of the period effect $\gamma_{n}$ can be obtained by estimating the earnings function in the
} native sample. The estimated coefficient can then be used to "solve out" the period effect from the immigrant earnings function.

${ }^{8}$ For simplicity, the cohorts that entered the country prior to 1965 or after 2000 are pooled into two separate groups when interacting with the years since migration variable. It is also possible to interact the higherorder years-since-migration variables with the vector of cohort fixed effects, but these higher-order interactions add little to the empirical analysis. 
report selected coefficients that conveniently illustrate the direction and magnitude of the level and growth cohort differences. ${ }^{9}$

Note that the regression model produces estimates of the cohort differences in wage levels that are closely aligned with the raw data in Table 1. For example, the regression model predicts an entry wage disadvantage of 21.3 percent for the cohort that entered the country in the late 1960s, while the raw data in Table 1 suggested a 23.5 percent wage disadvantage. Note also that the regression model documents that the decline in entry wages stopped somewhere around 1990, and suggests that there may have been a slight rebound since then.

To conveniently illustrate the trends in the rate of economic assimilation, I calculate the extent to which the wage gap between immigrants and natives narrowed over their first decade in the United States. ${ }^{10}$ The regression model reveals that the rate of economic assimilation began to decline noticeably with the immigrant cohort that arrived in the 1980s. Immigrants who arrived in the late 1960s could expect a 13-percentage point increase in relative earnings during their first decade in the country. However, the assimilation rate of the immigrants who entered in the late 1980s was about a third smaller (and the difference is statistically significant, with a $t$ statistic of -13.9), while the assimilation rate of the immigrants who entered in the late 1990s was close to zero.

There are two potential explanations for this slowdown in the rate of wage convergence. The first is that it represents a failure of the regression model to properly account for various factors that may be leading to lower relative wages for immigrants in recent years and that have nothing to do with the underlying process of human capital accumulation that is presumably the defining feature of the economic assimilation process. The second is that it reflects a tangible decline in the rate at which more recent immigrant waves accumulate marketable skills in the post-migration period. Before proceeding to discuss the plausibility of the second hypothesis, it is crucial to devote some effort to determining if the result "goes away" when the regression model is confronted with various sensitivity tests that attempt to more properly account for the evolution of wages in the native and immigrant populations.

\section{Period Effects}

Perhaps the most obvious explanation for the decline in the rate of economic assimilation is that the period effects restriction in equation (4) is false. In other words, changes in macroeconomic conditions differentially affect the earnings of immigrants and natives. It is well known (Katz and Murphy, 1992; Lemieux, 2006) that the returns to skills dramatically increased in the past few decades. Because the immigrant and native populations have a different skill mix, the assumption that the period effects are the same "on average" may not capture the impact of changing macroeconomic conditions on the two wage structures, biasing the estimates of the aging and cohort effects.

A straightforward way of allowing for differential period effects is to assume that the restriction in equation (4) operates at the level of a particular skill group at a particular point in time, rather than for the average immigrant and native worker at that point in time (Borjas, 1995; Lubotsky, 2011). Put differently, the period effect restriction should be skill-specific: changes in

9 The complete set of regression coefficients is available in the online appendix of the working paper version of this paper (Borjas, 2013).

10 The 10-year growth in the relative wage of immigrants is calculated by predicting immigrant and native $\log$ earnings both at the time of entry, assumed to occur at age 25, and 10 years later. 
macroeconomic conditions have the same proportionate impact on the wages of immigrants and natives in a particular skill group.

To examine the sensitivity of the results to the use of a skill-specific wage deflator, I classify all workers into one of 40 narrowly defined skill groups $(h)$ based on a worker's educational attainment and age. ${ }^{11}$ I use the 1970-2010 cross-sections to calculate the nominal rate of wage growth experienced by native workers in each of these groups over the four-decade period. Let $\varphi_{h \tau}$ be the implied price index that can be used to deflate the wages of a worker in skill group $h$ and in cross section $\tau$ calculated from the various Censuses. ${ }^{12}$ I then estimated the regression model using the skill-specific deflator $\varphi_{h \tau}$ to "solve out" the period effects from the earnings functions in $(2 a)$ and $(2 b)$. The operational assumption, of course, is that period effects are the same for natives and immigrants within a narrowly defined skill group.

Column 2 of Table 2 shows that controlling for skill-specific period effects reduces the rate of decline in the entry wage of immigrant cohorts. For example, the entry wage of the 19851989 cohort is about 14 percentage points lower than that of the 1965-1969 cohort in the simpler specification, but only 10 percentage points lower when the model adjusts for skill-specific period effects. This finding is similar to that reported in Lubotsky (2011), who uses a structural framework to estimate the changing price of skills over the period and concludes that changes in the wage structure can account for about a third of the observed decline in entry earnings typically associated with level cohort effects. ${ }^{13}$

Note, however, that accounting for skill-specific period effects also implies that the decline in "cohort quality" evident between 1965 and 1989 was effectively reversed in the subsequent two decades. Table 2 , in fact, suggests that the relative entry wage of the cohort that arrived in 2005-2009 was essentially the same as that of the cohort that arrived in 1965-1970, with both of these groups having a relative entry wage disadvantage of about 21 percent. As will be seen below, these trends in relative entry wages are partially explained by the changing national origin mix of the immigrant cohorts during the period.

Although the trend in immigrant entry wages is sensitive to the period effects assumption, the regression in column 2 shows that the finding of a decline in the rate of economic assimilation is impervious to the use of skill-specific wage deflators. In particular, the growth rate in the relative wage during the first decade is still about 5.0 percentage points lower for the 1985-1989 cohort (relative to the immigrants who entered in the late 1960s) and is not significantly different from zero for the cohort that entered in the late 1990s. ${ }^{14}$

The regression reported in column 3 of Table 2 controls for the variation in period effects across skill groups in a more general way. Instead of solving out the period effects by using the

${ }^{11}$ Specifically, workers are classified into one of 5 education groups and into one of 8 age groups, for a total of 40 skill groups. The five education groups are: high school dropouts, high school graduates, workers with some college, college graduates, and workers with more than a college education. The eight age brackets are given by: $25-29,30-34,35-39,40-44,45-49,50-54,55-59$, and 60-64.

12 Suppose that a particular cross-section is used as the baseline, then the implied price deflator for a specific skill group in cross-section $\tau$ would be given by ${ }_{h}=\bar{w}_{h} / \bar{w}_{h 0}$, where $\bar{w}_{h}$ gives the mean earnings of native workers in group $h$ in cross section $\tau$. The empirical analysis uses the 2000 cross-section as the baseline.

13 See also Barth, Bratsberg and Raaum (2004).

14 The $t$-statistic for the test of the difference in the 10-year relative growth rate between the 1965-1969 cohort and the 1985-1999 cohort is -22.3 . 
skill-specific wage deflators, the regression instead introduces the vector of 40 education-age fixed effects as regressors. This adjustment method, of course, controls both for differential period effects between immigrants and natives as well as for differences in skills among the groups, so that the resulting estimates of aging and cohort effects are not directly comparable to those that use the skill-specific wage deflators. Although adjusting for skill differences "flattens out" the variation in entry wages across cohorts, the regression coefficients still reveal a substantial decline in the rate of economic assimilation even within narrowly defined skill groups.

An alternative method of adjusting the data for skill-specific period effects is to define the skill groups in terms of their placement in the (weekly) earnings distribution. In particular, I classify all workers into one of 100 skill groups depending on the worker's percentile ranking in the native wage distribution. ${ }^{15}$ I then use the 1970-2010 cross-sections to measure the wage growth experienced by each percentile of the earnings distribution, and calculate the implied price index $\phi_{h \tau}$ that can be used to deflate the earnings of a worker in percentile ranking $h$ and in cross section $\tau$. Note that the use of this particular wage deflator ensures that the variance of the adjusted earnings distribution is constant over time. Column 4 of Table 2 shows that defining the skill groups in terms of a worker's percentile ranking produces results that closely resemble those obtained from using the education-age wage deflators in column $2 .{ }^{16}$

Finally, the last column of the table introduces a method that purges the data from any potential contamination caused by differential period effects in the native and immigrant wage distributions. In particular, I exploit the fact that, in each cross-section, the IPUMS provides a consistently defined measure of the worker's occupation using the 1990 occupational coding scheme. I used the 1990 Census to calculate the average log weekly wage associated with each occupation code. ${ }^{17}$ I then assigned each worker in the entire 1970-2010 pooled data this measure of "occupational earnings" (i.e., the average 1990 log weekly wage in the occupation). By construction, the change in the average occupational earnings of an immigrant cohort over time can only be attributed to a shift in the occupational distribution of the group.

Column 5 of Table 2 reports the estimated coefficients when the regression model uses the worker's log occupational earnings as the dependent variable. As in the regressions that use the worker's actual weekly earnings, the occupational earnings data suggest a decline in the relative entry wage of immigrants through 1990 (with a very slight rebound in the past two decades). The occupational earnings data also reveal a decline in the rate of "occupational assimilation" experienced by the more recent immigrant cohorts. The immigrants who arrived in the late 1960s experienced a 5-percentage point narrowing in the relative occupational wage during their first decade in the United States. The extent of occupational assimilation declined to

15 To minimize the potential problems caused by outlying or top-coded observations, the bottom 3 and top 3 percentiles are merged into two separate skill groups.

16 It would not be instructive to generalize this regression by adding the fixed effects indicating the worker's percentile as regressors since those fixed effects are essentially a nonlinear transformation of the dependent variable.

17 The calculation of the average log weekly wage in each occupation uses the sample of native men who report a valid occupation code. 
about 3 percent for the immigrants who entered in the late 1980s, and declined further to a statistically insignificant one percent for those who entered in the late 1990s. ${ }^{18}$

\section{The Changing Composition of the Immigrant Population}

It is evident that accounting for differential period effects cannot explain why the rate of economic assimilation declined so dramatically for the immigrant cohorts that entered the United States after the mid-1980s. There are, however, two obvious "compositional" changes that could potentially account for the declining assimilation rate. Specifically, the growth cohort effects may be attributable to the changing national origin mix of immigrants or to changes in the geographic sorting of immigrants across regions of the United States.

It is well known that a substantial part of the decline in the entry wage of successive immigrant cohorts through 1990 can be explained by the changing national origin mix of the immigrant population (Borjas, 1992). The national origin mix of the immigrant workforce, of course, is highly correlated with the skill composition of immigrant workers, and the changing national origin mix (i.e., away from developed countries in Western Europe to developing countries in Latin America and Asia) inevitably led to an immigrant population that was, on average, relatively less skilled. It seems possible that the changing national origin mix influences not only the wage level of the average immigrant, but the rate of growth in earnings as well.

Table 3 examines if the changing national origin mix of immigrants can account for the decline in assimilation rates. In particular, the second column of the table re-estimates the basic regression model after including a vector of national origin fixed effects (using the three-digit birthplace classification in the IPUMS that can be consistently defined between 1970 and 2010). ${ }^{19}$ Controlling for the changing national origin mix of immigrant by including a vector of around 100 national origin fixed effects does, in fact, greatly attenuate the shifts in entry wages observed across successive immigrant cohorts. Note, however, that the inclusion of national origin fixed effects barely affects the estimated rates of assimilation. Even within national origin groups, the 10-year growth in relative wages is around 10 percent for the late 1960s cohort, around 7 percent for the late 1980s cohort, and slightly negative for the late 1990s cohort.

The changing rate of assimilation could also be due to the changing geography of immigrant settlement in the United States. Fewer immigrants are now settling in the traditional immigrant-receiving states, and parts of the country where immigration was relatively rare historically (e.g., Arkansas and Georgia) now receive large numbers of foreign-born workers. This geographic diffusion could, in theory, alter the rate of economic progress of immigrants because there are dramatic geographic differences in the industrial and occupational mix of jobs, and these differences may stimulate or dampen the economic assimilation of newcomers.

Column 3 of Table 3 adds a vector of state-of-residence fixed effects to the regression model to determine if the results are sensitive to controlling for geographic location. It is evident that the inclusion of the state fixed effects does not alter any of the substantive findings.

The last column of Table 3 adds the education-age fixed effects defined earlier as regressors. The regression continues to reveal a substantial decline in the rate of economic

18 The $t$-statistic for the test of the difference in the 10-year relative growth rate between the 1965-1969 cohort and the 1985-1999 cohort is -13.3.

19 The IPUMS also provides a five-digit birthplace classification. I do not use the more detailed classification because the national origin information provided by the 1970 Census data is less detailed than that provided by subsequent censuses. 
assimilation even within skill groups, within national origin groups, and within geographic areas of settlement. In short, there does not seem to be a mechanical reason arising from changes in sample composition that can easily explain the cohort differences in the rate of assimilation that are so evident in the raw data.

\section{Selection into Employment}

As noted earlier, the "2010 census" data is drawn from the 2009-2011 pooled American Community Surveys. The use of the 2009-2011 ACS data can be problematic since the wage data in these surveys are likely to be contaminated by the substantial decline in work propensities associated with the Great Recession. Put differently, the labor supply effects of the severe economic downturn could generate selection biases that differentially affect the average wages of immigrant and native workers. ${ }^{20}$

The Great Recession had a particular adverse effect on the employment propensities of natives. The fraction of native men aged 25-64 who worked at least one week in the survey year declined from 90.8 percent in the 2000 census, to 89.6 percent in the pooled 2005-2007 ACS, to 86.1 in the pooled 2009-2011 ACS. In contrast, the fraction of immigrant men who worked at least one week in the year was more stable during the period: 89.3 percent in the 2000 census, 93.5 percent in the pooled 2005-2007 ACS, and 91.4 percent in the pooled 2009-2011 ACS. The relative decline in native employment propensities concurrent with the Great Recession could potentially generate a spurious slowdown in the rate of economic assimilation since the "surviving" natives in the workforce will likely have a higher average wage. ${ }^{21}$

It is easy to document that the relative decline in native employment after 2008 cannot account for the slowdown in the rate of economic assimilation. The simplest way of showing this is to redefine what is meant by the " 2010 census." In particular, the availability of annual ACS surveys (each comprising 1 percent of the population) suggests that I can re-estimate the regression model by defining the pooled 2005-2007 ACS surveys as the "2010 census" crosssection. This redefinition implies that the most recent data used in the empirical analysis was collected before the precipitous decline in native employment propensities. ${ }^{22}$

The second column of Table 4 shows that estimating the regression model using the pooled 2005-2007 ACS as the alternative sample yields almost identical results to those obtained when using the 2009-2011 ACS. ${ }^{23}$ The implied rate of economic assimilation experienced by the

20 This point, of course, is related to the analogous discussion of how differential employment trends between black and white workers affect the secular trend in the racial wage gap; see Butler and Heckman (1977) and Neal (2004).

${ }^{21}$ It is important to add that there was a long-term, but similar, decline in the employment propensities of immigrant and native men between 1970 and 2000. In 1970, 96.7 and 96.2 percent of immigrant and native men, respectively, worked during the survey year. In 2000, the respective statistics are 90.3 and 89.3 percent. The widening of the native-immigrant employment gap occurs mostly during the Great Recession.

22 Although the employment rates implied by the variable used in the analysis (whether the person works during the survey year) is somewhat stable across concurrent ACS and census surveys (e.g., in 2000), the employment and unemployment rates implied by other variables (particularly those referring to activity during the survey week) sometimes differ dramatically between the ACS, the decennial census, and the Current Population Surveys. To address these inconsistencies, the Bureau of the Census recently changed the way in which it collects employment information in the ACS (U.S. Bureau of the Census, 2009).

23 The regression that uses the 2005-2007 pooled ACS excludes the small sample of immigrants who entered the United States after 2005. These immigrants have been in the country for only about a year by the time 
various immigrant cohorts is roughly the same regardless of the data used. For example, the relative wage of the 1975-1979 cohort grew by 8.6 percentage points in the first 10 years in column 1 (which uses the 2009-2011 ACS), and by 8.9 percentage points in column 2 (which uses the 2005-2007 ACS). Similarly, the relative wage of the 1995-1999 cohort grew by about 2 to 4 percentage points in the first 10 years regardless of which data set is used. ${ }^{24}$ In short, the changing sample composition resulting from the relative decline in native employment cannot account for the decline in the rate of economic assimilation experienced by the most recent immigrant cohorts.

In fact, the data can be used in a more judicious way to further document that employment selectivity has little to do with the underlying trends in economic assimilation. I have already introduced a variable giving the (log) occupational earnings of a worker by assigning each worker the mean occupational earnings (measured as of 1990) of that worker's occupation at time $t$. It turns out that a person's occupation is reported not only for the sample of workers (i.e., persons who worked during the survey year), but also for persons who have worked at any time in the prior 5 years. ${ }^{25}$ Hence it is possible to re-estimate the occupational earnings regression by adding to the sample a large fraction of the men who were not working in the survey year.

Not surprisingly, a much greater and much more stable fraction of men aged 25-64 worked at some point in the prior 5 years, so that the changes in employment propensities across data sets are far smaller when using this alternative employment measure. The fraction of native men reporting an occupation, for example, declines from 94.8 percent in the 2000 Census, to 94.1 percent in the pooled 2005-2007 ACS, to 92.7 percent in the 2009-2011 ACS. Among immigrants, the respective statistics are 95.0 percent, 96.3 percent, and 95.6 percent.

The third column of Table 4 reproduces, for expositional convenience, the basic regression using log occupational earnings in the sample of current workers first reported in Table 2. Column 4 re-estimates the regression using the entire sample of persons who report an occupation in each cross-section, so that the sample now includes all persons who worked at some point in the prior 5 years. It is evident that the regression coefficients are similar to those obtained in column 3. Most important, the regression still documents a significant decline in the rate of economic assimilation over the first 10 years, from 5.1 percent for the 1965-1969 cohort to 2.3 percent for the 1995-1999 cohort (and the difference is statistically significant with a $t$ statistic of -7.5). Finally, column 5 re-estimates the regression using the 2005-2007 pooled ACS as the data for the "2010 census," so that there cannot be any impact of the Great Recession on employment propensities. The regression coefficients reported in the last two columns of Table 4 are essentially identical.

The evidence documented in Tables 2-4, therefore, suggest that it is unlikely that the decline in the rate of economic assimilation can be attributed to differential period effects between immigrants and natives, to compositional changes in the immigrant population, or to selection effects resulting from differential rates of withdrawal from the labor force during the

they are observed in the ACS. The results presented in this section are essentially identical if the regression were reestimated including this sample of immigrants.

24 In both regressions, there is a statistically significant difference between the rate of economic assimilation experienced by the 1965-1969 and the 1995-1999 cohorts. The t-statistic in columns 1 and 2 are -4.5 and -3.9 , respectively.

25 The 1970 Census reports occupation for persons who have worked at any time in the past 10 years. 
Great Recession. The evidence instead suggests that there may have been a tangible slowdown in the rate at which immigrants accumulate human capital after they migrate to the United States. ${ }^{26}$

\section{Human Capital Acquisition}

In fact, the Census data itself shows that such a slowdown in human capital acquisition may have occurred. The various surveys contain one variable that partially measures the changing human capital stock of immigrants during the assimilation period - the attainment of English language proficiency. Beginning with the 1980 Census, the data provides self-reported information on each immigrant's level of English proficiency. I use these data to define an indicator variable set to unity if the immigrant speaks only English or speaks English very well. I then estimated a descriptive regression model similar to that given by equation (1) to calculate the age-adjusted English language proficiency rate of each immigrant cohort in each crosssection. ${ }^{27}$ To ensure that it is possible to observe an increase in the rate of English language proficiency, the sample excludes both natives and immigrants who originated in one of the countries in the British "sphere of influence" where English is widely spoken by the foreign-born population at the time of entry. ${ }^{28}$

Table 5 reports the trends in the (age-adjusted) fraction of immigrants who are Englishproficient, both across cohorts and for a single cohort over time. Because the Census reports English language proficiency for all persons, regardless of whether a person is working or not, the trends on language proficiency can also be used to document the extent to which selection into employment may be driving the underlying evidence. The top panel of the table reports the trends in English language proficiency for the sample of men who worked during the survey year, while the bottom panel reports the trends using the entire sample of men. A comparison of the two panels shows that the trends are essentially identical regardless of the sample definition, so that selection into employment plays little role in determining the observed rate of human capital acquisition as measured by English language proficiency. I limit the discussion of the evidence to the trends reported in Panel B.

26 It is important to emphasize that the rate of economic assimilation that can be estimated from repeated cross sections suffers from a potentially important flaw. In particular, a fraction of the immigrants in a particular cohort are likely to return to their source countries (or migrate elsewhere), and the rate of economic assimilation is necessarily calculated from a sample that contains all immigrants at the beginning of the period and only the survivors at the end. Some studies in the literature use longitudinal samples to examine how non-random return migration affects the rate of economic assimilation implied by the repeated cross-section method. Hu (2000) and Lubotsky (2007), for example, employ datasets that match, at the individual level, demographic information from (relatively small) census-type surveys with the complete earnings histories of workers maintained by the Social Security Administration. These studies typically find that, at least in the pre-1990 period, the method of repeated cross-sections overestimates the rate of economic assimilation. See also Beenstock, Chiswick, and Paltiel (2010) and Duleep and Dowhan (2002).

27 The regression includes the worker's age, introduced as a third-order polynomial.

28 The excluded countries are Canada, Bermuda, Belize-British Honduras, Jamaica, Antigua-Barbuda, Bahamas, Barbados, Dominica, Grenada, St. Kitts-Nevis, St. Vincent, Trinidad and Tobago, Guyana/British Guiana, the United Kingdom, Ireland, Northern Ireland, Liberia, South Africa, Australia, and New Zealand. These countries were selected because English was the modal language spoken at home by immigrants from these countries even at the time of arrival. These countries account for 7.7 percent of all immigration and the fraction of newly arrived immigrants originating in these countries who speak English very well is 97.0 percent. The sample includes persons enrolled in school to capture the possibility that some of the English language investments are occurring in a formal environment. 
There was a clear break in the extent to which a particular cohort "picks up" English language skills beginning with the cohort that entered the United States around 1990. In particular, 30.4 percent of the immigrants who arrived in the country between 1975 and 1980 were English proficient at the time of arrival, and this fraction increased to 42.4 percent (or a 12.0 percentage point increase) by 1990. The proportion of English-proficient immigrants in this cohort increased further to 46.2 (another 4 percentage points) between 1990 and 2000.

In contrast, even though the immigrants who entered the country between 1985 and 1989 had similar initial conditions in terms of English proficiency (31.7 percent were English proficient at the time of arrival), the proficiency rate of this cohort increased by only about 4 percentage points during the first 10 years, far less than the 12 percentage increase experienced by the 1975-1979 cohort. Finally, note that the English proficiency rate of the cohort that arrived in 1995-2000 was essentially the same at the starting line (at 32.2 percent), but increased by only three percentage points during their first decade in the United States. ${ }^{29}$ Figure 1 dramatically illustrates the flattening in the slope of the age-language proficiency profile across subsequent immigrant cohorts. In short, there seems to be a potentially important link between the slowdown in the rate of economic assimilation and the slowdown in the rate at which immigrants acquire human capital in the post-migration period.

\section{A Model of Human Capital Accumulation and Economic Assimilation}

The available evidence suggests that the observed decline in the rate of economic assimilation is not a spurious finding resulting from changes in the wage structure, changes in the demographic composition of the immigrant population, or selectivity issues related to the decline in native employment propensities associated with the Great Recession. Instead, it seems to reflect a significant slowdown in the rate at which immigrants accumulate human capital after arriving in the United States. In order to identify the cause of the slowdown, therefore, it is useful to derive the implications of a model of optimal human capital accumulation for the rate of economic assimilation of immigrants.

A two-period model of the life cycle provides a simple framework for thinking about these questions. ${ }^{30}$ Let $K$ be the number of efficiency units an immigrant acquired in the source country. A fraction $\delta$ of these efficiency units are specific to the source country's labor market, so that the worker's marketable human capital in the post-migration period is $E=(1-\delta) K$. Note that the value of the depreciation parameter $\delta$ provides a simple way for contrasting the investment incentives faced by comparable immigrants and natives in the United States. The typical native can sell all of his $K$ efficiency units in the labor market, so that $\delta=0$ for natives and $0<\delta<1$ for immigrants.

An immigrant lives for two periods after migrating. During the investment period, the immigrant devotes a fraction $\pi$ of his human capital to the production of additional human capital, and this investment increases the number of marketable efficiency units in the payoff

29 The implicit assumption made in comparing the trends in the English language proficiency rate across cross-sections is that there are no period effects. Since there is no native baseline, it is difficult to imagine which deflator could be used to adjust the data.

30 The model presented below adapts the framework introduced in Borjas (2000). A more general theory would jointly consider the human capital investment decision, the decision to emigrate, and the possibility that the worker may reconsider the migration decision after "testing" the host country's labor market. 
period by $g \times 100$ percent. If the market-determined rental rate for an efficiency unit in the host country is one dollar, the present value of the post-migration income stream is:

$$
P V=(1-\delta) K(1-\pi)+\rho[(1-\delta) K(1+g)],
$$

where $\rho$ is the discounting factor.

The human capital production function that generates the increase in the number of marketable efficiency units is:

$$
g E=(K) K \text {, }
$$

with $\alpha<1$. The production function in (6) is a simple adaptation of the one in the classic BenPorath (1967) model of human capital accumulation. In that framework, a worker produces human capital by using part of his current human capital stock for the production of additional efficiency units. In equation (6), the worker uses a fraction of his entire human capital stock (or $\pi K)$ as an input in production. Therefore, even though part of the pre-existing human capital may not be marketable in the United States, it is still useful in the production of additional human capital. ${ }^{31}$ As an extreme example, an immigrant with highly specialized medical training may not be able to market his skills in the U.S. labor market due to licensing restrictions. Nevertheless, those skills do not entirely disappear; that knowledge is imbedded in the worker and would certainly be useful in the production of additional human capital.

As in the Ben-Porath model, the production function in equation (6) allows for the possibility that the worker's pre-existing human capital stock $K$ is an independent input in the production process. It may be the case, for instance, that immigrants with higher levels of preexisting human capital may be more efficient at acquiring additional human capital. It is analytically convenient to rewrite the human capital production function as:

$$
g=(1 \quad)^{1} \quad K^{+1} .
$$

Equation (7) directly relates the rate of human capital accumulation of marketable skills $(g)$ to the fraction of efficiency units used for investment purposes $(\pi)$. Define "relative neutrality" as the case where the rate of human capital accumulation of marketable skills is independent of the initial level of human capital, so $\alpha+\beta=1$. If $\alpha+\beta>1$, the rate of human capital accumulation is positively related to initial skills, or "relative complementarity." If $\alpha+\beta<1$, there is a negative relationship, or "relative substitutability." 32

Workers choose the value of $\pi$ that maximizes the present value of post-migration earnings. The implied optimal rate of accumulation of marketable efficiency units in the postmigration period is then given by:

31 This formulation implies that $\pi K$ units of human capital are "used up" in the production of additional human capital. The marketable human capital available to sell in the U.S. labor market during the investment period then equals $(1-\delta)(K-\pi K)=(1-\delta) K(1-\pi)$, as specified in equation (7).

32 The special case of "relative neutrality" is, of course, analogous to the neutrality assumption in the BenPorath model, where the marginal cost curve of producing human capital is independent of the worker's initial stock. 


$$
g=(\quad)^{\overline{1}}\left(\frac{1}{1}\right)^{\frac{1}{1}} K^{\frac{+1}{1}} .
$$

If there is relative complementarity, highly skilled immigrants acquire more human capital; if there is relative substitutability, the more skilled acquire less. Equation (8) also implies a positive relation between the rate of human capital accumulation $g$ and the depreciation parameter $\delta$. In fact, because $\delta=0$ for native workers, the model implies that immigrants are accumulating human capital at a faster rate than comparable natives. The intuition is obvious: For comparable levels of "true" skills, immigrants face lower forgone earnings (a fraction $\delta$ of the pre-existing human capital is not marketable in the United States), and hence have a greater incentive to acquire more skills. In short, the income-maximization hypothesis implies that immigrants devote a larger fraction of their resources to investment activities than comparable natives. Finally, equation (8) implies a positive relation between the rate of human capital accumulation and the discounting factor $\rho$. As a result, immigrants who discount their future U.S. earnings less heavily (i.e., a higher $\rho$ ) would invest more.

Let $\dot{w}$ be the rate of wage growth experienced by an immigrant in the United States. This rate of wage growth is given by: 33

$$
\dot{w}=\log \left(\frac{(1 \quad) K(1+g)}{(1 \quad) K(1 \quad)}\right) \approx g+.
$$

It is easy to show that:

$$
\begin{aligned}
& \frac{\dot{w}}{>} 0, \\
& \operatorname{sign} \frac{\dot{w}}{K}=\operatorname{sign}(+1), \\
& \operatorname{sign}\left(\left.\left.\frac{\partial \dot{w}}{\partial K}\right|_{>0} \frac{\partial \dot{w}}{\partial K}\right|_{=0}\right)=\operatorname{sign}(+1) . \\
& \stackrel{\dot{w}}{>} 0,
\end{aligned}
$$

Equation (10a) shows that the predicted rate of wage growth in the United States is larger for workers who have a larger $\delta$. This result immediately implies that immigrants will experience faster wage growth than comparable natives, so that optimal human capital investment behavior predicts a positive rate of economic assimilation. Interestingly, the model generates a positive rate of economic assimilation because, on average, immigrants are "different" from natives: immigrants start their working life in the host country at a disadvantage (some of their skills have depreciated because $\delta>0$ ) and have an incentive to catch up. Equation (10a) also implies that

33 The rate of economic assimilation is given by the difference between $\dot{w}$ and the rate of wage growth experienced by comparable native workers (or $\dot{w}$ evaluated at $\delta=0$ ). 
within the immigrant population, those immigrants originating in countries where the preexisting skills are least transferable to the host country will experience a faster rate of postmigration wage growth.

Equation (10b) implies that the sign of the correlation between the rate of wage growth and the pre-existing human capital stock depends on whether there is relative substitution between pre- and post-migration human capital $(\alpha+\beta-1<0)$, or relative complementarity $(\alpha+$ $\beta-1>0$ ). Equation (10c) reports the analogous result in terms of the rate of economic assimilation: high-skill immigrants assimilate faster only if there is relative complementarity in the production of human capital.

Finally, equation $(10 d)$ implies that immigrants who are less likely to discount their future earnings in the U.S. labor market (i.e., have a higher $\rho$ ) will experience a higher rate of wage growth. This result suggests, for example, that immigrants who face higher costs for return migration will assimilate more quickly.

\section{Determinants of Economic Assimilation}

The analysis uses the 1980-2010 census extracts described earlier. ${ }^{34}$ By definition, an immigrant cohort now comprises a group of foreign-born persons who migrated to the United States at age $i$, from country $k$, at a particular calendar time $t .{ }^{35}$ For each $(i, k, t)$ cell, I calculate the mean log weekly wage as well as the fraction of persons in the group who are English proficient. The calculation of the mean log weekly wage uses the education-age deflator introduced earlier to allow for differential period effects across skill groups. The wage growth experienced by this cohort across censuses - relative to the wage growth experienced by a comparably aged group of native workers over the same period-measures the rate of economic assimilation for each cohort. The change in the rate of English proficiency across Censuses is one measure of the volume of human capital investments undertaken in the post-migration period.

The empirical analysis uses the sample of immigrant men originating in the largest 80 sending countries. These countries accounted for 93.5 percent of the foreign-born workforce in 2000. The analysis uses three age-at-migration "windows" to construct the cohorts: persons who were 25-34, 35-44, and 45-54 as of the time of arrival. The analysis also uses six year-of-arrival groups: immigrants who arrived in 1970-1974, 1975-1979, 1980-1984, 1985-1989, 1990-1994, and 1995-1999. The construction of the aggregate data ensures that the assimilation process is being observed among immigrants who arrived in the United States as adults. Each $(i, k, t)$ cohort is then tracked over the first ten years after arrival by "jumping" to the next cross-section and observing the now-older group at that point.

It is well known that there are sizable wage differences across immigrants belonging to different national origin groups. Not surprisingly, there are equally large differences in the rates of economic assimilation and human capital accumulation. The first three columns of Table 6 report the first-decade wage growth experienced by immigrants in the 10 largest national origin

\footnotetext{
34 The 1970 Census data is not used in this section because it lacks information on English language proficiency and offers a much less detailed classification of country of origin than subsequent censuses.

35 More precisely, the age-at-migration is given by the age of the immigrant at the time that he is first enumerated in a U.S. Census.
} 
groups who were 25-34 years old when they entered the country (relative to that experienced by comparably aged natives).

Chinese immigrants who arrived in the United States between 1995 and 1999 experienced a relative wage increase of 23.0 percentage points during their first 10 years in the country. In contrast, the growth rate was -4.4 percent for Cuban immigrants, -6.3 percent for Mexican immigrants, +10.2 percent for Filipino immigrants, and +11.6 percent for Indian immigrants. Interestingly, all of these large national origin groups exhibit a decline in the rate of assimilation between the cohorts that entered in the late 1980s and the late 1990s. Among Indians, for example, the rate of assimilation for those who entered in the late 1980s was 13 percentage points greater than for those who entered in the late 1990s.

The last three columns of Table 6 also reveal sizable differences in the rate of human capital accumulation, as measured by the change in the English proficiency rate. ${ }^{36}$ For example, the fraction of immigrants who speak English very well increased by 3.3 percentage points for persons who migrated from El Salvador in the late 1990s. The respective growth rate is 1.3 percent for Mexican immigrants, 9.8 percent for Cuban immigrants, and 12.4 percent for Filipino immigrants. In addition, most of the groups (7 out of 10) exhibit a decline in the growth rate of English language proficiency between the cohorts that entered in the late 1980s and the late 1990s. The 10-year growth rate in English language proficiency fell from 3.2 to 1.3 percent for Mexican immigrants, 15.6 to 9.8 percent for Guatemalan immigrants, and from 5.4 percent to 0.6 percent for Vietnamese immigrants.

The human capital model presented in the previous section provides a useful framework for thinking about (and interpreting) the cross-country variation in the rates of human capital accumulation and economic assimilation, and for examining the extent to which changes in the underlying determinants can account for the slowdown in economic assimilation. The model isolates three variables that play a central role in the investment decision: the initial human capital stock of the cohort $(K)$; the degree to which the pre-existing skills of the cohort are specific to the country of origin $(\delta)$; and the cohort's discounting factor $(\rho)$. The empirical analysis presented below attempts to determine if empirical proxies for these variables can explain the disparity in assimilation rates documented in Table 6.

Consider initially the determinants of the rate of economic assimilation. The regression model is given by:

$$
\Delta \log w_{i k}(t)=\phi_{i}+\phi_{t}+Z_{k}(t) \beta+\varepsilon,
$$

where $\Delta \log w_{i k}(t)$ gives the 10-year change in the log weekly wage of a cohort of immigrants who arrived in the United States at age $i$, from country $k$, at time $t$ relative to the wage growth experienced by comparably aged natives during the same decade; $Z$ is a vector of country specific characteristics that may determine the rate of economic assimilation; and $\phi_{i}$ and $\phi_{t}$ are vectors of fixed effects that absorb any age- and year-of-arrival-specific factors. The excluded year-of-arrival fixed effect indicates if the immigrant cohort arrived in the United States between 1975 and 1979, so that the cohort fixed effects measure the rate of assimilation relative to this cohort.

36 The English language proficiency rates are calculated in the sample of all men in the relevant cohort (rather than just workers). 
I first estimate a regression model that only includes the two vectors of fixed effects as regressors. Not surprisingly, the first column of Table 7 reports sizable cohort differences (i.e., the values of $\phi_{t}$ ) in the rate of economic assimilation. Specifically, the assimilation rate of the cohort that arrived in the late 1990s is 9.4 percentage points lower than that of the cohort that arrived in the late 1970s. Although the table only reports the estimated cohort fixed effects for two of the cohorts, it is worth emphasizing that the regression includes the entire vector of $\phi_{t}$.

The empirical analysis uses the cohort's average years of educational attainment (measured at the time of arrival) to approximate for the pre-existing human capital stock $K$. The second column of Table 7 shows that this variable has a strong positive impact on the rate of economic assimilation. Each additional year of education increases the (relative) rate of wage growth by 0.6 percentage points. The evidence, therefore, supports the conjecture of relative complementarity in the production of human capital: more skilled immigrants invest more in U.S.-specific human capital and experience a higher rate of economic assimilation subsequently.

The regression in column 2 also includes a variable measuring the log per-capita GDP in the country of origin at the time of migration. ${ }^{37}$ It is well known that there exists a strong positive correlation between immigrant earnings and per-capita GDP in the source country. This correlation is typically explained by arguing that the skills of immigrants from high-income countries are more easily transferable to the U.S. labor market, so that per-capita GDP may be an inverse proxy for the rate of depreciation $\delta$. Table 7 shows that the per-capita GDP variable has a negative impact on relative wage growth. The negative effect is consistent with the theoretical prediction. Holding initial skills constant, the immigrants who can most easily transfer their skills from one industrialized economy to another are also the immigrants who find it most expensive to invest in the post-migration period.

Note, however, that controlling for the cohort's educational attainment and per-capita GDP of the country of origin does not "explain" the decline in assimilation rates observed across cohorts. The cohort that entered the country in the late 1990s is still predicted to have a rate of assimilation that is 9.1 percentage points lower than that of the cohort that entered in the late 1970s.

The third column of Table 7 adds variables that proxy for the discounting factor $\rho$. First, immigrants originating in countries that are at least 3,000 miles away from the United States have a faster rate of assimilation (although the coefficient is not statistically significant). One potential explanation is that these immigrants face a higher cost of return migration, so that they are less likely to discount their future earnings in the United States. Similarly, the regression includes a civil liberties index constructed by Freedom House (2011). ${ }^{38}$ Immigrants from countries with repressive regimes have a larger rate of economic assimilation, presumably again because they are less likely to engage in return migration and do not heavily discount their future earnings in the United States. Note, however, that the inclusion of these additional variables in the regression model does not explain the lower assimilation rate of the cohort that arrived in the

37 The per-capita GDP variable is drawn from the Penn World Table (Heston et al. 2012) and gives the (PPP-adjusted) real per-capita GDP at the start of the five-year period that defines a year-of-entry cohort.

38 Freedom House (2011) constructs an index of civil liberties annually for each country in the world. The index ranges from 1 to 7 , with seven being assigned to the countries with the most oppressive regimes. The variable used in the regression classifies a country as "repressive" if the index is 4 or greater, and is evaluated during the decade when the immigrant cohort arrived. 
United States in the late 1990s. The relative decline experienced by this cohort stands stubbornly at 9.3 percentage points.

The payoff for immigrants to learning the English language (and perhaps engaging in other forms of U.S.-specific human capital investments) likely depends on the frequency with which they will use those skills in their everyday interactions (Lazear, 1999). Immigrants who find relatively few of their compatriots living in the United States typically have a stronger incentive to make the U.S.-specific investments that will allow a wider range of social and economic exchanges. In contrast, immigrants who enter the country and find a large welcoming ethnic enclave have much less incentive to engage in these types of investments since they will find a large market for their pre-existing skills.

The human capital model presented in the previous section defines the human capital stock that an immigrant can market in the United States as $(1-\delta) K$. It is easy to imagine that the fraction of the human capital stock that survives in the post-migration period depends on the size of the "audience" that will value the cohort's skills in the United States. An increase in the preexisting size of the national origin group likely implies that a larger fraction of the skills of new immigrant arrivals will survive the move.

I use two variables to test the hypothesis that "group size" influences the cohort's rate of assimilation. The first is the "effective" number of immigrants from that country who already reside in the United States, where the effective size of national origin group $k$ gives the expected number of immigrants that a randomly chosen newcomer from that country can potentially interact with in the marketplace. Obviously, the effective size of a national origin group depends not only on the actual size of the pre-existing group of immigrants, but on their geographic distribution as well. After all, for any given stock, economic and social exchanges are far more likely to occur if type- $k$ immigrants cluster in a small number of localities. Let $s_{k r}(t)$ be the share of pre-existing immigrants from group $k$ who reside in state $r$ at time $t$, and $N_{k r}(t)$ be the number of such immigrants. The expected number of type- $k$ immigrants that "surround" a randomly chosen newcomer can then be defined by: ${ }^{39}$

$$
\bar{N}_{k}(t)={ }_{r} s_{k r}(t) N_{k r}(t)
$$

The second variable gives the "effective" number of immigrants who are in the same linguistic group, where a linguistic group is defined by the set of immigrants who share the same mother tongue. ${ }^{40}$ Suppose immigrants from country $k$ are in linguistic group $g$, and that there are $A_{g r}(t)$ pre-existing immigrants from that linguistic group residing in state $r$. The effective number of linguistically compatible immigrants is then given by:

$$
\bar{A}_{k}(t)={ }_{r} s_{k r}(t) A_{g r}(t)
$$

${ }^{39}$ It is easy to show that $\bar{N}_{k}(t)=N_{k}(t) H_{k}(t)$, where $N_{k}(t)$ is the total size of the national origin group and $H$ is the Herfindahl index measuring the geographic clustering of type- $k$ immigrants.

40 A country's "mother tongue" is defined as the language that most newly arrived immigrants from that country speak at home. 
To an important extent, the variable measuring the size of the linguistic group differs from the variable measuring the size of the national origin group only for Hispanic immigrants. The size of the national origin group within the Hispanic population may be small in some cases (e.g., immigrants from Ecuador), but the size of the linguistic group is much larger because there exists a numerically sizable audience with whom Hispanic immigrants can use their pre-existing language skills to frequently and cheaply carry out social and economic exchanges. ${ }^{41}$

Column 4 of Table 7 introduces the vector $\left(\bar{N}_{k}, \bar{A}_{k}\right)$ into the cross-country regression and shows that the effective size of the national origin group has a strong negative effect on the rate of economic assimilation, but the impact of the size of the linguistic group, although negative, is numerically weaker and insignificant. 42 The magnitude of the impact of "own" group size on economic assimilation is sizable: If the size of the effective group increases by 1 million persons, the rate of economic assimilation falls by 3.8 percentage points. ${ }^{43}$ Equally important, the introduction of these variables "nudges" the size of the cohort effects. After controlling for group size, the relative decline in the rate of economic assimilation experienced by the cohort that entered in the late 1990s falls from 9.3 to 7.2 percentage points. In other words, the increasing size of the immigrant national origin group accounts for about 20 percent of the decline in the rate of economic assimilation. It seems, therefore, that the increasing size of immigrant groups is correlated with the decline in the rate of economic assimilation observed across successive entry cohorts. ${ }^{44}$

To demonstrate the link between the determinants of the rate of economic assimilation and the rate of human capital acquisition, I estimated a similar set of cross-country regressions using the growth rate in the fraction of the group that is English proficient as the dependent variable. More precisely, I estimate the regression model in equation (13) using the dependent variable $\Delta p_{i k}(t)$, which gives the 10-year change in the probability that immigrants who arrived in the United States at age $i$, from country $k$, at time $t$ speak only English or speak English very well.

To ensure that the growth rate in English proficiency is a sensible measure of human capital accumulation for the immigrant cohort, I limit the regression to cohorts originating in countries outside the British "sphere of influence," so that, at least in principle, there could have

41 The calculation of the variables $N_{k r}(t)$ and $A_{g r}(t)$ only use immigrants who arrived prior to the cohort that entered the country in year $t$. The geographic sorting of type- $k$ immigrants is obtained from the census crosssection in which the immigrant cohort is first enumerated. These statistics are calculated using the entire population of native- and foreign-born persons, regardless of age.

${ }^{42}$ I also estimated regression specifications that separated the two components of the effective size of a group. Both the actual size of the group and the group's Herfindahl index tend to have negative effects on the rate of economic assimilation. The coefficients in the specification analogous to that reported in column 4 of Table 7 are: national origin group size: -.012 (.004); linguistic group size: -.004 (.002); Herfindahl index: -.168 (.070). In addition, the coefficient measuring the fixed effect for the 1995-1999 entry cohort is -.065 (.021).

43 For the cohort that arrived between 1995 and 2000, there were 113,000 "effective" immigrants from Jamaica; 301,000 from the Philippines; 389,000 from Cuba; and 1.8 million from Mexico.

44 It could be argued that the size of the national origin group may be reflecting a labor demand effect: the wage falls as the group's size increases. Note, however, that the neoclassical labor demand model would imply that it is the change in the size of the group that leads to a change in the wage. The regressions reported in Table 7 conduct a different conceptual experiment, correlating the future change in the wage with the pre-existing size of the group. 
been an increase in the English language proficiency rate of the immigrant cohort. This restriction reduces the number of countries in the data from 80 to 69.

Table 8 summarizes the regression results. The first column again reports the coefficients of the cohort fixed effects $\phi_{t}$. It is evident that the immigrants who entered the country in the late 1980s or 1990s have around a 7-percentage point lower rate of increase in the English proficiency rate than those who entered in the late 1970s. As the second column of Table 8 shows, the group's initial human capital (as measured by educational attainment) has a positive impact on the rate of English language acquisition. Each additional year of pre-acquired education increases the growth in the English proficiency rate by nearly 1 percentage point. The evidence, therefore, again supports the conjecture of relative complementarity in the production of human capital.

Finally, as the regression in the last column shows, the inclusion of the group size variables attenuates the magnitude of the cohort effects in the rate of human capital accumulation. ${ }^{45}$ Note that the (national origin) group size variable has a strong negative effect: a one million-person increase in the size of the effective national origin group reduces the growth rate in English proficiency by 5.0 percentage points. The size of the linguistic group again has a negative, but weaker, effect. Finally, the coefficient of the relative cohort effect for the immigrants who entered in the late 1990s declines from -7.2 percent to -4.8 percent, so that the increasing size of the effective national origin group (and presumably the corresponding reduction in the incentives to invest in human capital) accounts for about a third of the decline in the rate of human capital investments across the cohorts. 46

It is easy to demonstrate that the results are not driven solely by the remarkable growth of Hispanic immigration in the United States. Table 9 reports selected coefficients when the regressions exclude either Mexican immigrants (in Panel A) or all Hispanic immigrants (in Panel B). Since Mexicans account for nearly a third of all immigrants in the United States and the regressions are (approximately) weighted by the sample size of a cohort, the massive size of the Mexican cohorts could easily be distorting the results. As the coefficients reported in Panel A show, however, the evidence is generally robust to the exclusion of Mexican immigrants from the analysis.

Panel B of the table goes a step further and excludes all Hispanic immigrants. The sample of 80 countries of origin now becomes a sample of 62 countries in the regressions on the rate of economic assimilation, and of 51 countries in the regressions on the rate of language acquisition

\footnotetext{
45 I also estimated country-level regression models using the rate of "occupational assimilation" introduced earlier as the dependent variable. The coefficients from these regressions tell a consistent story. In particular, the coefficient of the 1995-1999 cohort effect in column 3 is -.016 (.007), and falls to -.006 (.009) when the group size variables are included. The coefficients of the group size variables are: effective size of national origin group: -.009 (.006); effective size of linguistic group: -.010 (.007).

46 The regression results reported in Tables 8 and 8 can be interpreted as reduced-form coefficients from a structural model that relates the rate of economic assimilation to the rate of human capital accumulation. The key coefficient in the structural model would measure the rate of return to English proficiency. Unfortunately, none of the country-specific variables used in the reduced-form regressions provide valid instruments to estimate the structural parameter. The rate of wage growth in the model of human capital accumulation presented earlier is given by $\dot{w}=g+$, where $g$ is the rate of human capital accumulation and $\pi$ measures the fraction of human capital freed up for labor market uses as the individual ages. Both $g$ and $\pi$ depend on all the key parameters of the model (i.e., the initial human capital stock, $K$; the depreciation rate, $\delta$; and the discounting factor, $\rho$ ). Hence none of the countryspecific variables that proxy for these underlying parameters can be a valid instrument in a regression of $\dot{w}$ on $g$.
} 
(since these regressions also exclude countries in the British sphere of influence). The results are somewhat robust to this major specification change. In view of the evidence reported in previous sections, it is not surprising that there is a slowdown in both the rate of assimilation and the rate of language acquisition even among non-Hispanic immigrants. However, it seems that group size plays a weaker role in accounting for the decline in the rate of human capital acquisition.

In sum, the regressions consistently identify one factor-namely, national origin group size - that is partly responsible for the observed decline in the rate of economic assimilation. As a result, the evidence suggests a potentially important hypothesis that is certain to become the focus of much research: the more recent immigrant cohorts have fewer incentives to invest in U.S.-specific human capital because the growth of the immigrant population makes those investments less profitable than they once were, and those reduced incentives have slowed the rate of economic assimilation. ${ }^{47}$

\section{Summary}

This paper uses data drawn from the 1970-2010 decennial U.S. censuses to document and examine the long-run trends in immigrant earnings over the past few decades. Perhaps the main finding of the paper is that there are cohort effects not only in the entry wage of immigrants, with more recent cohorts having relatively lower entry wages, but there are also cohort effects in the rate of growth of earnings, with more recent cohorts having a much smaller rate of economic assimilation.

The crucial question, of course, is whether the decline in the rate of wage convergence represents a "true" decline in the rate of human capital accumulation or a spurious correlation caused by other factors. The analysis reported in this paper conducted a number of sensitivity tests to establish that the decline in the rate of economic assimilation was not due to the possibility that: (1) period effects change the wage structures of immigrants and natives differently; (2) the changing national origin composition of immigrants may lead to an immigrant population where the "average" immigrant is now less likely to assimilate; (3) the changing geographic settlement of immigrants in the United States has reduced the assimilation rate of the typical immigrant; and (4) the employment effects of the Great Recession generate selection biases that differentially contaminate the growth rate of average earnings for immigrants and natives.

Instead, the data seem to suggest that at least part of the decline in assimilation reflects a measurable reduction in the actual rate of human capital accumulation. In particular, the more recent immigrant cohorts are improving their English language skills at a far slower rate than earlier cohorts. In fact, the study identifies one factor that seems to explain part of the decline in both the rate of economic assimilation and the rate of English language acquisition: the rapid growth in the size of specific national origin groups in the United States. New immigrants are less likely to assimilate and to invest in human capital the larger the pre-existing size of the national origin group in the United States. The growth in the size of national origin groups

${ }^{47}$ It would be interesting to examine the trends in other types of human capital investments undertaken by the immigrant workforce. After all, English language proficiency only plays a limited (though important) role in determining the value of the stock of marketable human capital. The decennial censuses contain one other variable (i.e., educational attainment) that could be used to examine such trends. Unfortunately, the coding of the education variable changes capriciously from one census to the next. As a result, it cannot be used to construct a consistently defined measure of "average years of education" that could be differenced within a cohort to measure the volume of educational investments. 
accounts for about a quarter of the decline in the rates of human capital acquisition and economic assimilation.

Because of the potential significance of the evidence, it is prudent to conclude by stressing the need for caution in the interpretation of the findings and the need for replication of the results before we can unequivocally assert that the trends revealed by the Census data describe an important part of the immigrant experience in the U.S. labor market. Moreover, although the analysis conducted a large number of sensitivity tests to determine if the decline in economic assimilation arises "spuriously," I suspect that many other such tests can be (and should be) designed and carried out. It is obviously important to determine precisely the extent to which the earnings trends reported in this paper can be attributed to concurrent changes in the rate of human capital acquisition. 


\section{References}

Abramitzky, Ran, Leah Platt Boustan, and Katherine Eriksson. 2012. A nation of immigrants: Assimilation and economic outcomes in the age of mass migration. Stanford University.

Antecol, Heather, Peter J. Kuhn, and Stephen J. Trejo. 2006. Assimilation via prices or quantities? Sources of immigrant earnings growth in Australia, Canada, and the United States. Journal of Human Resources 41: 821-840.

Aydemir, Abdurrahman, and Mikal Skuterud. 2005. Explaining the deteriorating entry earnings of Canada's immigrant cohorts, 1966-2000. Canadian Journal of Economics 38: 641-672.

Baker, Michael, and Dwayne Benjamin. 1994. The performance of immigrants in the Canadian labor market. Journal of Labor Economics 12: 369-405.

Barth, Erling, Bernt Bratsberg and Oddbjørn Raaum. 2004. Identifying earnings assimilation of immigrants under changing macroeconomic conditions. Scandinavian Journal of Economics 106: 1-22.

Beenstock, Michael, Barry R. Chiswick, and Ari Paltiel. 2010. Testing the immigrant assimilation hypothesis with longitudinal data. Review of the Economics of the Household 8: 727.

Ben-Porath, Yoram. 1967. The production of human capital and the life cycle of earnings. Journal of Political Economy 75: 352-365.

Borjas, George J. 1985. Assimilation, changes in cohort quality, and the earnings of immigrants. Journal of Labor Economics 3: 463-489.

Borjas, George J. 1992. National Origin and the Skills of Immigrants in the Postwar Period. In: George J. Borjas and Richard B. Freeman, eds., Immigration and the work force: Economic consequences for the United States and source areas, 17-47. Chicago: University of Chicago Press.

Borjas, George J. 1995. Assimilation and changes in cohort quality revisited: What happened to immigrant earnings in the 1980s? Journal of Labor Economics 13: 201-245.

Borjas, George J. 2000. The economic progress of immigrants. In: George J. Borjas, ed., Issues in the economics of immigration, 15-49. Chicago: University of Chicago Press.

Borjas, George J. 2013. The Slowdown in the Economic Assimilation of Immigrants: Aging and Cohort Effects Revisited Again. NBER Working Paper No. 19116.

Borjas, George J., and Rachel M. Friedberg. 2009. Recent trends in the earnings of new immigrants to the United States. NBER Working Paper no. 15406. 
Butler, Richard and James J. Heckman, 1977. "The Government's Impact on the Labor Market Status of Black Americans: A Critical Review," in Equal Rights and Industrial Relations, Leonard J. Hausman et al. (Eds.). (Madison, WI: Industrial Relations Research Association): 235-281.

Chiswick, Barry R. 1978. The effect of Americanization on the earnings of foreign-born men. Journal of Political Economy 86: 897-921.

Chiswick, Barry R. 1986. Is the new immigration less skilled than the old? Journal of Labor Economics 4:168-192.

Chiswick, Barry R., and Paul W. Miller. 1999. English language fluency among immigrants in the United States. Research in labor economics 17: 151-200.

Chiswick, Barry R., and Paul W. Miller. 2005. Linguistic distance: A quantitative measure of the distance between English and other languages. Journal of Multilingual and Multicultural Development 26: 1-11.

Douglas, Paul H. 1919. Is the new immigration more unskilled than the old? Journal of the American Statistical Association 16: 393-403.

Duleep, Harriet Orcutt, and Daniel J. Dowhan 2002. Insights from longitudinal data on the earnings growth of U.S. foreign-born men. Demography 39: 485-506.

Duleep, Harriet Orcutt, and Mark C. Regets. 1997. Immigrant entry earnings and human capital growth: Evidence from the 1960-1980 censuses. Research in Labor Economics 16: 297-317.

Edin, Per Anders, Robert J. LaLonde, and Olof Åslund. 2000. Emigration of immigrants and measures of immigrant assimilation: Evidence from Sweden. Swedish Economic Policy Review 7: 163-204.

Freedom House. 2011. Freedom in the world 2011: Tables, graphs, and other supporting documents. Washington, DC: Freedom House.

Funkhouser, Edward, and Stephen J. Trejo. 1995. The labor market skills of recent male immigrants: Evidence from the Current Population Survey. Industrial and Labor Relations Review 48: 792-811.

Green, David A. 1999. Immigrant occupational attainment: Assimilation and mobility over time. Journal of Labor Economics 17: 49-79.

Guiso, Luigi, Paola Sapienza, and Luigi Zingales. 2009. Cultural biases in economic exchange. Quarterly Journal of Economics 124: 1095-1131. 
Heston, Alan, Robert Summers and Bettina Aten. 2012. Penn world table version 7.1. Philadelphia, PA: Center for International Comparisons of Production, Income and Prices at the University of Pennsylvania.

$\mathrm{Hu}$, Wei-Yin. 2000. Immigrant earnings assimilation: Estimates from longitudinal data. American Economic Review 90: 368-372.

Isphording, Ingo E., and Sebastian Otten. 2012. The costs of Babylon: Linguistic distance in applied economics. Ruhr Economic Paper no. 337.

Katz, Lawrence F., and Kevin M. Murphy. 1992. Changes in the wage structure, 1963-87:

Supply and demand factors. Quarterly Journal of Economics 107: 35-78.

LaLonde, Robert J., and Robert H. Topel. 1992. The assimilation of immigrants in the U.S. labor market. In: George J. Borjas and Richard B. Freeman, eds., Immigration and the work force: Economic consequences for the United States and source areas, 67-92. Chicago: University of Chicago Press.

Lazear, Edward P. 1999. Culture and language. Journal of Political Economy 107: S95-S126.

Lemieux, Thomas. 2006. Increasing residual wage inequality: Composition effects, noisy data, or rising demand for skill? American Economic Review 96: 461-498.

Lubotsky, Darren. 2007. Chutes or ladders? A longitudinal analysis of immigrant earnings. Journal of Political Economy 115: 820-867.

Lubotsky, Darren. 2011. The effect of changes in the U.S. wage structure on recent immigrants' earnings. Review of Economics and Statistics 93: 59-71.

Neal, Derek. 2004. "The Measured Black-White Wage Gap among Women is Too Small," Journal of Political Economy 112 (February): S1-S28.

Schoeni, Robert F. 1997b. New evidence on the economic progress of foreign-born men in the 1970s and 1980s. Journal of Human Resources 32: 683-740.

U.S. Bureau of the Census. 2009. Changes to the American Community Survey between 2007 and 2008 and the Effect on the Estimates of Employment and Unemployment. Washington, DC. 
Figure 1. Aging profile for the relative wage of immigrants, by cohort

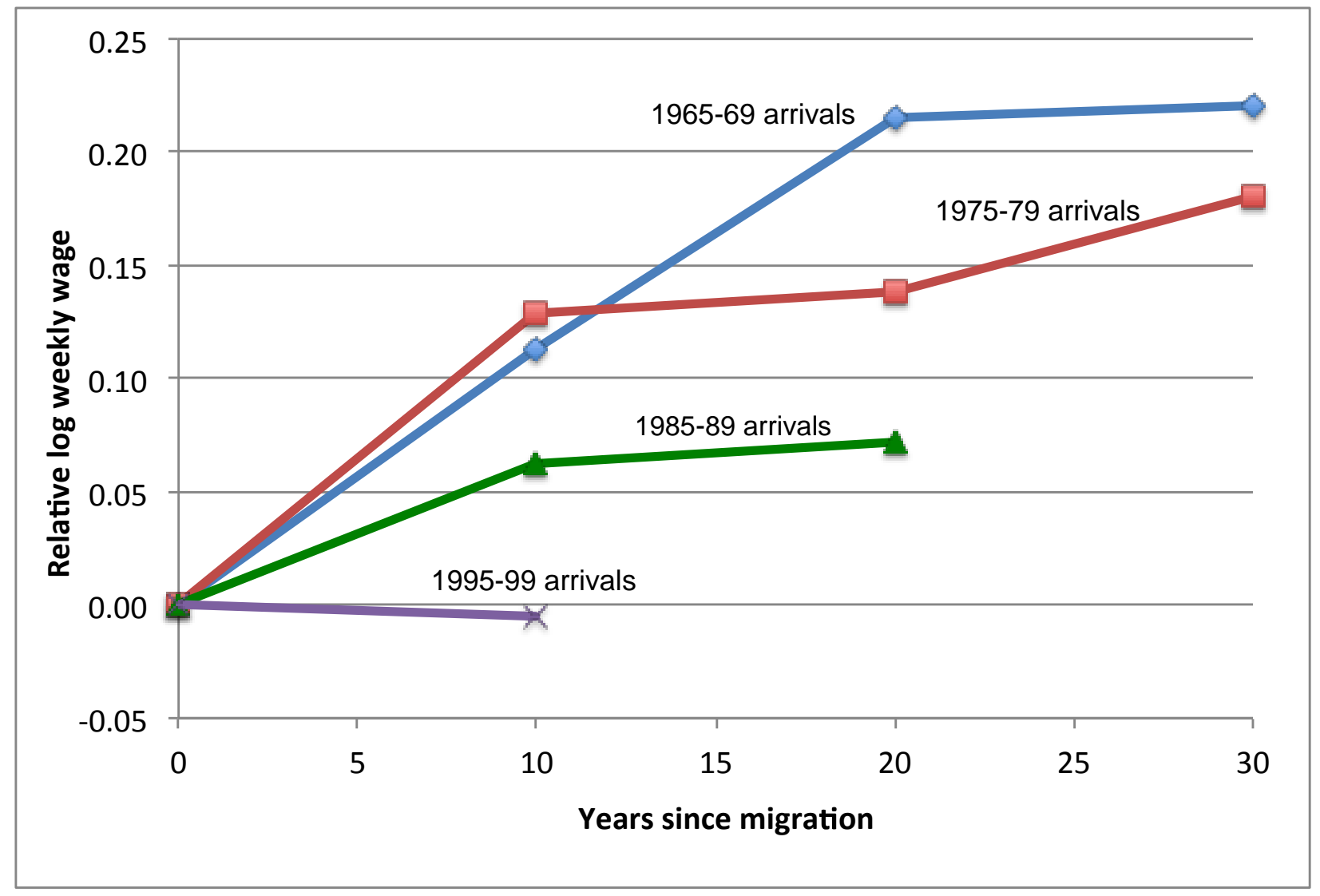

Notes: The aging profiles are obtained from the data reported in Table 2 . The relative log weekly wage of each immigrant cohort is normalized to zero at the time of entry. 
Figure 2. Aging profile of English language proficiency, by cohort

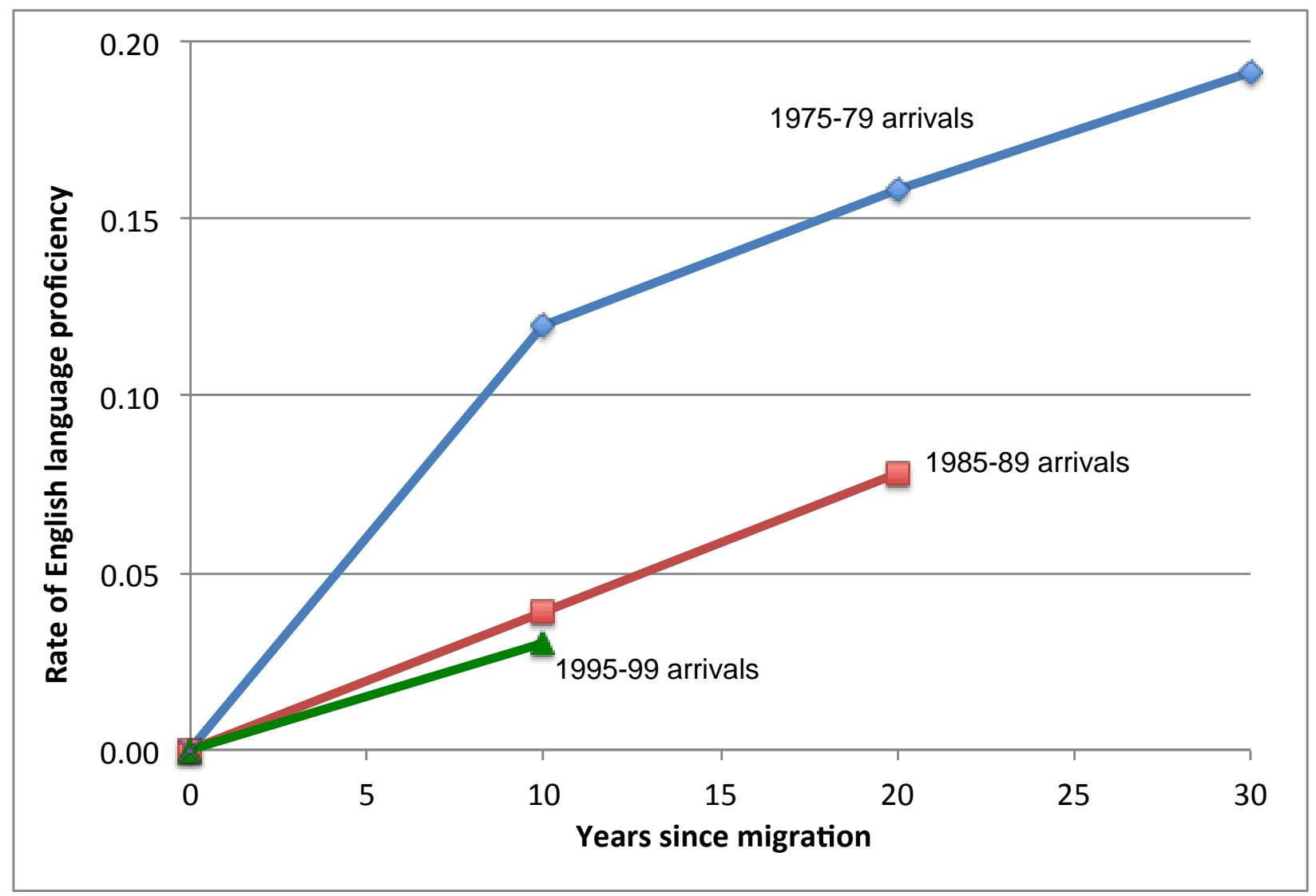

Notes: The aging profiles are obtained from the data reported in Table 6. The rate of English language proficiency of each immigrant cohort is normalized to zero at the time of entry and is calculated in then sample of immigrants originating in countries outside the British sphere of influence. 


\section{Table 1. Age-adjusted relative weekly earnings of immigrant cohorts, by census cross-section}

\begin{tabular}{lccccc} 
Cohort: & 1970 & 1980 & 1990 & 2000 & 2010 \\
\cline { 2 - 6 } $2005-2009$ arrivals & --- & --- & --- & --- & -.326 \\
2000-2004 arrivals & --- & --- & --- & --- & -.349 \\
& & & & & $(.003)$ \\
$1995-1999$ arrivals & --- & --- & --- & -.273 & -.278 \\
$1990-1994$ arrivals & --- & --- & --- & -.269 & -.271 \\
& & & & $.003)$ & $(.003)$ \\
$1985-1989$ arrivals & --- & --- & -.331 & -.269 & -.259 \\
& & & $(.001)$ & $(.002)$ & $(.005)$ \\
$1980-1984$ arrivals & --- & --- & -.285 & -.236 & -.206 \\
& & & $(.001)$ & $(.002)$ & $(.006)$ \\
$1975-1979$ arrivals & --- & -.314 & -.185 & -.176 & -.134 \\
$1970-1974$ arrivals & & $(.001)$ & $(.001)$ & $(.005)$ & $(.004)$ \\
& --- & -.223 & -.124 & -.128 & -.053 \\
$1965-1969$ arrivals & -.235 & -.122 & -.020 & -.014 & .205 \\
$1960-1964$ arrivals & $(.001)$ & $(.001)$ & $(.003)$ & $(.005)$ & $(.010)$ \\
& -.058 & -.041 & .046 & .074 & --- \\
$1950-1959$ arrivals & $(.001)$ & $(.001)$ & $(.004)$ & $(.004)$ & \\
& .037 & .032 & .100 & .147 & --- \\
& $(.001)$ & $(.001)$ & $(.003)$ & $(.010)$ &
\end{tabular}

Notes: Standard errors are reported in parentheses and are clustered at the cohort level. The age-adjusted wage differentials between each immigrant cohort and natives are calculated from a regression estimated separately in each cross-section where the dependent variable gives the log weekly earnings of a worker and the regressors include the worker's age (introduced as a third-order polynomial). The age-adjusted relative wages are calculated at the mean level of age. The regressions also include a fixed effect for the residual immigrant cohort that arrived before 1950. The "2010" data is composed of the pooled 2009-2011 American Community Surveys. The "alternative 2010 data" is composed of the pooled 2005-2007 ACS. The number of observations in the regressions are: 1970, 945,579; 1980, 2,002,074; 1990, 2,373,285; 2000, 2,708,438; and 2010, 1,653,425. 


\section{Table 2. Generalized regression model allowing for cohort effects in both wage levels and wage growth rates}

\begin{tabular}{|c|c|c|c|c|c|}
\hline Cohort: & $\begin{array}{c}\text { 1. Basic } \\
\text { specification }\end{array}$ & $\begin{array}{l}2 \text { Using } \\
\text { education- } \\
\text { age deflator }\end{array}$ & $\begin{array}{l}\text { 3. Using } \\
\text { education- } \\
\text { age fixed } \\
\text { effects }\end{array}$ & $\begin{array}{l}\text { 4. Using } \\
\text { percentile } \\
\text { deflator }\end{array}$ & $\begin{array}{l}\text { 5. Using } \\
\text { occupational } \\
\text { earnings }\end{array}$ \\
\hline \multicolumn{6}{|l|}{ Relative entry wage: } \\
\hline \multirow[t]{2}{*}{ 1965-1969 arrivals } & -.213 & -.206 & -.153 & -.227 & -.108 \\
\hline & $(.020)$ & $(.028)$ & $(.018)$ & $(.026)$ & $(.012)$ \\
\hline \multirow[t]{2}{*}{$1975-1979$ arrivals } & -.301 & -.261 & -.191 & -.279 & -.138 \\
\hline & $(.020)$ & $(.029)$ & $(.017)$ & $(.027)$ & $(.012)$ \\
\hline \multirow[t]{2}{*}{$1985-1989$ arrivals } & -.349 & -.303 & -.198 & -.326 & -.201 \\
\hline & $(.019)$ & $(.028)$ & $(.018)$ & $(.026)$ & $(.012)$ \\
\hline \multirow[t]{2}{*}{ 1995-1999 arrivals } & -.270 & -.251 & -.133 & -.259 & -.171 \\
\hline & $(.016)$ & $(.021)$ & $(.018)$ & $(.021)$ & $(.011)$ \\
\hline \multirow[t]{2}{*}{ 2005-2009 arrivals } & -.300 & -.212 & -.163 & -.231 & -.188 \\
\hline & $(.037)$ & $(.033)$ & $(.018)$ & $(.036)$ & $(.036)$ \\
\hline \multicolumn{6}{|l|}{$\begin{array}{l}\text { Relative wage growth } \\
\text { in first } 10 \text { years: }\end{array}$} \\
\hline \multirow[t]{2}{*}{$1965-1969$ arrivals } & .132 & .112 & .123 & .132 & .048 \\
\hline & $(.024)$ & $(.038)$ & $(.019)$ & $(.036)$ & $(.015)$ \\
\hline \multirow[t]{2}{*}{$1975-1979$ arrivals } & .111 & .086 & .105 & .088 & .031 \\
\hline & $(.025)$ & $(.039)$ & $(.019)$ & $(.037)$ & $(.015)$ \\
\hline \multirow[t]{2}{*}{$1985-1989$ arrivals } & .090 & .063 & .076 & .064 & .034 \\
\hline & $(.024)$ & $(.038)$ & $(.019)$ & $(.035)$ & $(.015)$ \\
\hline \multirow[t]{2}{*}{ 1995-1999 arrivals } & .025 & .039 & .007 & .019 & .011 \\
\hline & $(.020)$ & $(.025)$ & $(.019)$ & $(.026)$ & $(.013)$ \\
\hline
\end{tabular}

Notes: Standard errors are reported in parentheses and are clustered at the cohort level. The regressions have $9,682,801$ observations. The dependent variable in columns 1-4 uses the worker's log weekly wage; the dependent variable in column 5 is the worker's log occupational wage, given by the average log weekly earnings (measured as of 1990) in the worker's occupation. All regressions include the worker's age (introduced as a third-order polynomial) fully interacted with a variable indicating if the person is foreign- or native-born. The calculation of the relative wage growth in the first 10 years assumes that the immigrant arrives in the United States at age 25. 
Table 3. Sensitivity of estimated cohort effects to compositional changes

\begin{tabular}{|c|c|c|c|c|}
\hline Cohort: & $(1)$ & $(2)$ & (3) & $(4)$ \\
\hline \multicolumn{5}{|l|}{ Relative entry wage: } \\
\hline 1965-1969 arrivals & $\begin{array}{l}-.206 \\
(.028)\end{array}$ & $\begin{array}{l}-.296 \\
(.067)\end{array}$ & $\begin{array}{l}-.356 \\
(.081)\end{array}$ & $\begin{array}{l}-.319 \\
(.096)\end{array}$ \\
\hline 1975-1979 arrivals & $\begin{array}{l}-.261 \\
(.029)\end{array}$ & $\begin{array}{l}-.298 \\
(.066)\end{array}$ & $\begin{array}{l}-.380 \\
(.079)\end{array}$ & $\begin{array}{l}-.295 \\
(.095)\end{array}$ \\
\hline 1985-1989 arrivals & $\begin{array}{l}-.303 \\
(.028)\end{array}$ & $\begin{array}{l}-.310 \\
(.067)\end{array}$ & $\begin{array}{l}-.404 \\
(.077)\end{array}$ & $\begin{array}{l}-.292 \\
(.095)\end{array}$ \\
\hline 1995-1999 arrivals & $\begin{array}{l}-.251 \\
(.021)\end{array}$ & $\begin{array}{l}-.226 \\
(.071)\end{array}$ & $\begin{array}{l}-.277 \\
(.079)\end{array}$ & $\begin{array}{l}-.193 \\
(.097)\end{array}$ \\
\hline 2005-2009 arrivals & $\begin{array}{l}-.212 \\
(.033)\end{array}$ & $\begin{array}{l}-.208 \\
(.071)\end{array}$ & $\begin{array}{l}-.301 \\
(.078)\end{array}$ & $\begin{array}{l}-.215 \\
(.093)\end{array}$ \\
\hline \multicolumn{5}{|l|}{ Relative wage growth in first } \\
\hline 1965-1969 arrivals & $\begin{array}{c}.112 \\
(.038)\end{array}$ & $\begin{array}{c}.078 \\
(.024)\end{array}$ & $\begin{array}{c}.072 \\
(.017)\end{array}$ & $\begin{array}{c}.140 \\
(.017)\end{array}$ \\
\hline 1975-1979 arrivals & $\begin{array}{c}.086 \\
(.039)\end{array}$ & $\begin{array}{c}.061 \\
(.024)\end{array}$ & $\begin{array}{c}.062 \\
(.017)\end{array}$ & $\begin{array}{c}.112 \\
(.016)\end{array}$ \\
\hline 1985-1989 arrivals & $\begin{array}{c}.063 \\
(.038)\end{array}$ & $\begin{array}{c}.045 \\
(.024)\end{array}$ & $\begin{array}{c}.047 \\
(.017)\end{array}$ & $\begin{array}{c}.082 \\
(.016)\end{array}$ \\
\hline 1995-1999 arrivals & $\begin{array}{c}.039 \\
(.025)\end{array}$ & $\begin{array}{l}-.011 \\
(.019)\end{array}$ & $\begin{array}{l}-.042 \\
(.017)\end{array}$ & $\begin{array}{c}.005 \\
(.019)\end{array}$ \\
\hline Controls for: & & & & \\
\hline Country of origin & No & Yes & Yes & Yes \\
\hline State of residence & No & No & Yes & Yes \\
\hline Education-age deflator & Yes & Yes & Yes & No \\
\hline Education-age fixed effects & No & No & No & Yes \\
\hline
\end{tabular}

Notes: Standard errors are reported in parentheses and are clustered at the cohort level. The regressions in columns 1 and 2 have 9,682,801 observations; the regressions in columns 3 and 4 have 9,367,529 observations. All regressions include the worker's age (introduced as a third-order polynomial) fully interacted with a variable indicating if the person is foreign- or native-born. The calculation of the relative wage growth in the first 10 years assumes that the immigrant arrives in the United States at age 25. 
Table 4. Sensitivity of estimated cohort effects to selectivity in employment

\begin{tabular}{|c|c|c|c|c|c|}
\hline \multirow[b]{2}{*}{ Cohort: } & \multicolumn{2}{|c|}{ Actual earnings } & \multicolumn{3}{|c|}{ Occupational Earnings } \\
\hline & $(1)$ & $(2)$ & (3) & $(4)$ & $(5)$ \\
\hline \multicolumn{6}{|l|}{ Relative entry wage: } \\
\hline $1965-1969$ arrivals & $\begin{array}{l}-.206 \\
(.028)\end{array}$ & $\begin{array}{l}-.208 \\
(.032)\end{array}$ & $\begin{array}{l}-.108 \\
(.012)\end{array}$ & $\begin{array}{l}-.109 \\
(.011)\end{array}$ & $\begin{array}{l}-.111 \\
(.008)\end{array}$ \\
\hline $1975-1979$ arrivals & $\begin{array}{l}-.261 \\
(.029)\end{array}$ & $\begin{array}{l}-.261 \\
(.032)\end{array}$ & $\begin{array}{l}-.138 \\
(.012)\end{array}$ & $\begin{array}{l}-.138 \\
(.010)\end{array}$ & $\begin{array}{l}-.145 \\
(.008)\end{array}$ \\
\hline $1985-1989$ arrivals & $\begin{array}{l}-.303 \\
(.028)\end{array}$ & $\begin{array}{l}-.301 \\
(.028)\end{array}$ & $\begin{array}{l}-.201 \\
(.012)\end{array}$ & $\begin{array}{l}-.201 \\
(.011)\end{array}$ & $\begin{array}{l}-.206 \\
(.007)\end{array}$ \\
\hline 1995-1999 arrivals & $\begin{array}{l}-.251 \\
(.021)\end{array}$ & $\begin{array}{l}-.249 \\
(.024)\end{array}$ & $\begin{array}{l}-.171 \\
(.011)\end{array}$ & $\begin{array}{l}-.178 \\
(.011)\end{array}$ & $\begin{array}{l}-.180 \\
(.007)\end{array}$ \\
\hline 2005-2009 arrivals & $\begin{array}{l}-.212 \\
(.033)\end{array}$ & --- & $\begin{array}{l}-.188 \\
(.036)\end{array}$ & $\begin{array}{l}-.175 \\
(.037)\end{array}$ & --- \\
\hline \multicolumn{6}{|l|}{$\begin{array}{l}\text { Relative wage growth in } \\
\text { first } 10 \text { years: }\end{array}$} \\
\hline $1965-1969$ arrivals & $\begin{array}{c}.112 \\
(.038)\end{array}$ & $\begin{array}{c}.117 \\
(.042)\end{array}$ & $\begin{array}{l}.048 \\
(.015)\end{array}$ & $\begin{array}{c}.051 \\
(.013)\end{array}$ & $\begin{array}{l}.053 \\
(.012)\end{array}$ \\
\hline $1975-1979$ arrivals & $\begin{array}{l}.086 \\
(.039)\end{array}$ & $\begin{array}{l}.089 \\
(.043)\end{array}$ & $\begin{array}{l}.031 \\
(.015)\end{array}$ & $\begin{array}{l}.035 \\
(.013)\end{array}$ & $\begin{array}{l}.043 \\
(.013)\end{array}$ \\
\hline $1985-1989$ arrivals & $\begin{array}{c}.063 \\
(.038)\end{array}$ & $\begin{array}{c}.062 \\
(.036)\end{array}$ & $\begin{array}{c}.034 \\
(.015)\end{array}$ & $\begin{array}{l}.038 \\
(.013)\end{array}$ & $\begin{array}{l}.046 \\
(.010)\end{array}$ \\
\hline 1995-1999 arrivals & $\begin{array}{l}.039 \\
(.025)\end{array}$ & $\begin{array}{l}.019 \\
(.026)\end{array}$ & $\begin{array}{l}.011 \\
(.013)\end{array}$ & $\begin{array}{l}.023 \\
(.012)\end{array}$ & $\begin{array}{l}.022 \\
(.008)\end{array}$ \\
\hline \multicolumn{6}{|l|}{ Sample: } \\
\hline Uses 2009-2011 ACS & Yes & No & Yes & Yes & No \\
\hline Uses 2005-2007 ACS & No & Yes & No & No & Yes \\
\hline $\begin{array}{l}\text { Includes non-workers } \\
\text { who report an occupation }\end{array}$ & No & No & No & Yes & Yes \\
\hline \multicolumn{6}{|c|}{$\begin{array}{l}\text { Notes: Standard errors are reported in parentheses and are clustered at the cohort level. The dependent variable in } \\
\text { columns } 1-2 \text { uses the worker's log weekly wage, deflated by the education-age deflator; the dependent variable in } \\
\text { column } 3-5 \text { is the worker's log occupational wage, given by the average log weekly earnings (measured as of } 1990) \\
\text { in the worker's occupation. The regressions reported in columns (2) and (5) exclude the immigrants who entered the } \\
\text { United States after } 2005 \text {. The number of observations in the regressions are: columns } 1 \text { and } 3,9,682,801 \text {; column } 2 \text {, } \\
9,731,901 ; \text { column } 4,10,268,321 \text {; and column } 5,10,282,258 \text {. All regressions include the worker's age (introduced } \\
\text { as a third-order polynomial) fully interacted with a variable indicating if the person is foreign- or native-born. The } \\
\text { regression in column } 5 \text { includes the worker's years of educational attainment interacted with a variable indicating if } \\
\text { the person is foreign- or native-born. The calculation of the relative wage growth in the first } 10 \text { years assumes that } \\
\text { the immigrant arrives in the United States at age } 25 \text {. }\end{array}$} \\
\hline
\end{tabular}

Actual earnings

$(.028)$

$(.032)$

$-.261$

$(.029)$

$(.032)$

$(.028)$

$-.249$

$(.021)$

$(.024)$

$-.212$

$(.033)$

.112

.117

.089

(.043)

(.036)

.019

(.026) 


\section{Table 5. Age-adjusted probabilities of speaking English very well, by year}

$\underline{\text { Sample }}$

A. Working men

2005-2009 arrivals

2000-2004 arrivals

1995-1999 arrivals

1990-1994 arrivals

1985-1989 arrivals

1980-1984 arrivals

1975-1979 arrivals

1970-1974 arrivals

B. All men

2005-2009 arrivals

2000-2004 arrivals

1995-1999 arrivals

1990-1994 arrivals

1985-1989 arrivals

1980-1984 arrivals

1975-1979 arrivals

1970-1974 arrivals

\begin{tabular}{cccc}
1980 & 1990 & 2000 & 201 \\
\hline--- & --- & --- & .32 \\
--- & --- & --- & .32 \\
--- & --- & .339 & .36 \\
--- & --- & .353 & .38 \\
--- & .336 & .363 & .403 \\
--- & .376 & .416 & .45 \\
.322 & .433 & .471 & .502 \\
.376 & .487 & .527 & .57
\end{tabular}

$\begin{array}{llll}--- & --- & --- & .313 \\ --- & --- & --- & .313 \\ --- & --- & .322 & .352 \\ --- & --- & .345 & .375 \\ --- & .317 & .356 & .395 \\ --- & .364 & .407 & .450 \\ .304 & .424 & .462 & .495 \\ .370 & .478 & .517 & .575\end{array}$

Notes: The age-adjusted probability of speaking English very well is calculated from a linear probability model estimated separately in each cross-section. The dependent variable is a dummy variable set to unity if the immigrant speaks only English or speaks English very well and zero otherwise, and the regressors include the worker's age (introduced as a third-order polynomial). The sample consists of immigrants originating in countries outside the British sphere of influence. The age-adjusted probabilities are calculated at the mean level of age. Although the standard errors are not reported, they typically lie between .01 and .02, even after clustering at the cohort level. The number of observations in the regressions reported in the top panel are: 1980, 97,910; 1990, 164,399; 2000, 284,790; $2010,190,935$. The respective numbers of observations in the bottom panel are: 109,320; 184,$626 ; 322,341$; and 210,374 
Table 6. Summary statistics for immigrants arriving in the United States at ages 25-34 (by country of origin and year-of-arrival)

\begin{tabular}{|c|c|c|c|c|c|c|}
\hline \multirow[b]{2}{*}{ National origin: } & \multicolumn{3}{|c|}{ Rate of economic assimilation } & \multicolumn{3}{|c|}{$\begin{array}{c}\text { Increase in rate of English } \\
\text { language proficiency }\end{array}$} \\
\hline & $1975-79$ & 1985-89 & $1995-99$ & $1975-79$ & $1985-89$ & $1995-99$ \\
\hline Mexico & 0.025 & 0.060 & -0.063 & 0.085 & 0.032 & 0.013 \\
\hline El Salvador & 0.128 & 0.112 & 0.036 & 0.067 & 0.070 & 0.033 \\
\hline Guatemala & 0.119 & 0.073 & -0.020 & 0.204 & 0.076 & 0.018 \\
\hline Cuba & 0.150 & 0.179 & -0.044 & 0.119 & 0.156 & 0.098 \\
\hline Dominican Republic & 0.095 & -0.087 & -0.159 & 0.158 & -0.004 & -0.001 \\
\hline China & 0.102 & 0.430 & 0.230 & 0.039 & 0.137 & 0.112 \\
\hline Korea & 0.265 & 0.121 & -0.078 & 0.109 & 0.011 & 0.100 \\
\hline Philippines & 0.203 & 0.178 & 0.102 & 0.142 & 0.097 & 0.124 \\
\hline Vietnam & 0.183 & 0.157 & -0.099 & 0.122 & 0.054 & 0.006 \\
\hline India & 0.333 & 0.246 & 0.116 & 0.136 & 0.087 & 0.059 \\
\hline
\end{tabular}

Notes: The rate of economic assimilation gives the rate of wage growth experienced by the immigrant cohort during the first decade in the United States relative to that experienced by comparably aged native workers, using the education-age specific deflator. The rate of English language acquisition gives the increase in the fraction of the cohort that speaks only English or speaks English very well over the first decade in the United States and is calculated using the sample of all men in the relevant cohort. 
Table 7. Determinants of economic assimilation in first 10 years

Variable:

Arrived in 1985-1989

\begin{tabular}{cccc}
$(1)$ & $(2)$ & $(3)$ & $(4)$ \\
\hline-.026 & -.020 & -.025 & -.022 \\
$(.023)$ & $(.022)$ & $(.020)$ & $(.021)$ \\
-.094 & -.091 & -.093 & -.072 \\
$(.016)$ & $(.016)$ & $(.017)$ & $(.021)$ \\
--- & .006 & .004 & .001 \\
& $(.002)$ & $(.003)$ & $(.004)$ \\
--- & -.024 & -.019 & -.014 \\
& $(.007)$ & $(.009)$ & $(.011)$ \\
--- & --- & .022 & .039 \\
& & $(.015)$ & $(.023)$ \\
& & .024 & .009 \\
& & $(.020)$ & $(.022)$ \\
--- & --- & --- & -.038 \\
& & & $(.015)$ \\
--- & --- & --- & -.009 \\
& & & $(.013)$
\end{tabular}

Notes: Standard errors are reported in parentheses and are clustered at the source country level. The unit of observation in the regression is an immigrant cohort defined by age at arrival, source country, and year of arrival. The regressions are weighted by $n_{0} n_{1} /\left(n_{0}+n_{1}\right)$, where $n_{0}$ is the sample size used to calculate the cohort's mean log wage at the beginning of the decade and $n_{1}$ is the respective sample size at the end of the decade. The regressions have 1,430 observations and include vectors of fixed effects indicating the age at arrival and the calendar year of entry. The excluded cohort fixed effect indicates if the immigrants arrived between 1975 and 1979. The rate of economic assimilation gives the rate of wage growth experienced by the immigrant cohort during the first decade in the United States relative to that experienced by comparably aged native workers, using the education-age deflator. 
Table 8. Determinants of increase in English language proficiency in first 10 years

Variable:

Arrived in 1985-1989

Arrived in 1995-1999

Educational attainment of cohort at time of entry

Log per-capita GDP of source country

Repressive government in source country

Geographic distance from U.S. (=1 if > 3000 miles)

Effective number of immigrants from source country (in millions)

Effective number of linguistic compatriots (in millions)

\begin{tabular}{cccc}
$(1)$ & $(2)$ & $(3)$ & $(4)$ \\
\hline-.064 & -.066 & -.066 & -.061 \\
$(.008)$ & $(.007)$ & $(.008)$ & $(.008)$ \\
-.065 & -.074 & -.072 & -.048 \\
$(.010)$ & $(.010)$ & $(.010)$ & $(.010)$ \\
--- & .007 & .006 & .002 \\
& $(.001)$ & $(.002)$ & $(.001)$ \\
--- & .011 & .012 & .018 \\
& $(.004)$ & $(.004)$ & $(.003)$ \\
--- & --- & .004 & .022 \\
& & $(.010)$ & $(.006)$ \\
--- & --- & .013 & -.007 \\
& & $(.014)$ & $(.014)$ \\
--- & --- & --- & -.050 \\
& & & $(.007)$ \\
--- & --- & --- & -.006 \\
& & & $(.009)$
\end{tabular}

Notes: Standard errors are reported in parentheses and are clustered at the source country level. The unit of observation in the regression is an immigrant cohort defined by age at arrival, source country, and year of arrival. The regressions are weighted by $n_{0} n_{1} /\left(n_{0}+n_{1}\right)$, where $n_{0}$ is the sample size used to calculate the cohort's English proficiency rate at the beginning of the decade, $n_{1}$ is the respective sample size at the end of the decade, and the English proficiency rate is calculated using the sample of all men in the relevant cohort. The regressions exclude source countries in the British sphere of influence. The regressions have 1,233 observations and include vectors of fixed effects indicating the age at arrival and the calendar year of entry. The omitted cohort fixed effect indicates if the immigrants arrived between 1975 and 1979. 


\section{Table 9. Sensitivity of results to the growth of Hispanic immigration}

Variable:

\section{A. Excluding Mexicans Arrived in 1985-1989}

Arrived in 1995-1999

Size of national origin group (in millions)

Size of linguistic compatriots (in millions)

B. Excluding Hispanics

Arrived in 1985-1989

Arrived in 1995-1999

Size of national origin group (in millions)

Size of linguistic compatriots (in millions)

\begin{tabular}{c}
$\begin{array}{c}\text { Rate of economic } \\
\text { assimilation }\end{array}$ \\
\hline$(1) \quad(2)$ \\
\hline
\end{tabular}

$-.044$

$(.019)$

$-.084$

(.021)

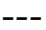

$---$

$---$

$-.036$

(.019)

$-.066$

(.022)

$-.217$

(.078)
$-.014$

(.015)

$(.022)$

$-.068$

(.026)

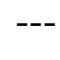

$--$
$-.032$

(.022)

$-.061$

(.024)

$-.306$

(.171)

.101

(.115)
English language proficiency

(1) (2)

(1) (2)

$-.063$

$-.060$

(.010)

(.010)

$-.048$

$-.055$

(.010)

$-.123$

(.035)

$-.011$

(.009)

(.011)

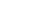

$---$

$-.058$

(.012)

$-.043$

(.012)

$-.079$

(.136)

(.114)

Notes: Standard errors are reported in parentheses and are clustered at the source country level. The unit of observation in the regression is an immigrant cohort defined by age at arrival, source country, and year of arrival.

The regressions are weighted by $n_{0} n_{1} /\left(n_{0}+n_{1}\right)$, where $n_{0}$ is the sample size used to calculate the cohort's log wage or English proficiency rate at the beginning of the decade, $n_{1}$ is the respective sample size at the end of the decade, and the English proficiency rate is calculated using the sample of all men in the relevant cohort. The regressions on the English language proficiency rate exclude source countries in the British sphere of influence. The regressions that exclude the Mexican national origin group have 1,412 observations when the dependent variable is the rate of economic assimilation and 1,215 observations when the dependent variable is the rate of English language acquisition. The sample sizes in the non-Hispanic sample are 1,107 and 910 observations, respectively. All regressions include vectors of fixed effects indicating the age at arrival and the calendar year of entry, the cohort's educational attainment at the time of entry, the log per capita GDP of the source country, a variable indicating whether the source country had a repressive regime, and a variable indicating if the country is "far" from the United States (i.e., more than 3,000 miles). The omitted cohort fixed effect indicates if the immigrants arrived between 1975 and 1979. 